\title{
META-ANALYTIC REVIEWS ON THE EFFICACY OF ADULT AND YOUTH MENTAL HEALTH COURTS
}

\author{
by \\ Nicole Hammond \\ BA Psychology, Carleton University, 2010
}

\begin{abstract}
A thesis submitted to the Faculty of Graduate and Postdoctoral Affairs in partial fulfillment of the requirements for the degree of Master of Arts in Psychology
\end{abstract}

Carleton University

Ottawa, Canada

C2012 Nicole Hammond 
Library and Archives

Canada

Published Heritage

Branch

395 Wellington Street

Ottawa ON K1A ON4

Canada
Bibliothèque et

Archives Canada

Direction du

Patrimoine de l'édition

395 , rue Wellington

Ottawa ON K1A ON4

Canada
Your file Votre référence

ISBN: 978-0-494-93574-3

Our file Notre référence

ISBN: $978-0-494-93574-3$
NOTICE:

The author has granted a nonexclusive license allowing Library and Archives Canada to reproduce, publish, archive, preserve, conserve, communicate to the public by telecommunication or on the Internet, loan, distrbute and sell theses worldwide, for commercial or noncommercial purposes, in microform, paper, electronic and/or any other formats.

The author retains copyright ownership and moral rights in this thesis. Neither the thesis nor substantial extracts from it may be printed or otherwise reproduced without the author's permission.
AVIS:

L'auteur a accordé une licence non exclusive permettant à la Bibliothèque et Archives Canada de reproduire, publier, archiver, sauvegarder, conserver, transmettre au public par télécommunication ou par l'Internet, prêter, distribuer et vendre des thèses partout dans le monde, à des fins commerciales ou autres, sur support microforme, papier, électronique et/ou autres formats.

L'auteur conserve la propriété du droit d'auteur et des droits moraux qui protege cette thèse. $\mathrm{Ni}$ la thèse ni des extraits substantiels de celle-ci ne doivent être imprimés ou autrement reproduits sans son autorisation.
In compliance with the Canadian Privacy Act some supporting forms may have been removed from this thesis.

While these forms may be included in the document page count, their removal does not represent any loss of content from the thesis.
Conformément à la loi canadienne sur la protection de la vie privée, quelques formulaires secondaires ont été enlevés de cette thèse.

Bien que ces formulaires aient inclus dans la pagination, il n'y aura aucun contenu manquant. 


\begin{abstract}
Over the past decade mental health courts have proliferated in an attempt to divert persons with mental illness from the traditional criminal justice system to a type of court (MHC) that is considered to be better equipped to handle their more complex needs. The overall aim of this thesis was to conduct a critical evaluation of the unpublished and published MHC literature. Meta-analytic reviews were employed to quantitatively explore the efficacy of MHCs in reducing criminal offenses, recidivism, and improving clinical outcomes in young and adult offenders across Canada and the United States. A total of 15 MHC sites were included in each of the reviews on criminal offences while 5 studies were included in the review of clinical outcomes. Summary effect sizes demonstrated that MHCs are related to reductions in criminal offences when comparing criminal offences prior to and following MHC involvement $(d=-.37)$, and that MHC participants recidivated less than comparison samples following MHC involvement $(d=-.19)$. Studies with higher levels of internal validity were found to be related to a smaller reduction in recidivism. Results showed that $\mathrm{MHC}$ participation is not related to improvements in clinical outcomes $(d=-.02)$. More rigorous studies comparing MHC effectiveness to preexisting established practices is needed.
\end{abstract}




\section{MENTAL HEALTH COURTS: META-ANALYTIC REVIEWS}

\section{Acknowledgements}

I would like to thank my supervisor, Dr. Robert Hoge, for his kindness and support over the course of my degree. Without his guidance this project would not have been possible. Finally, I would like to extend my gratitude to Dr.'s Shelley Brown and Kevin Nunes for their invaluable advice. 


\section{Table of Contents}

Abstract. .ii

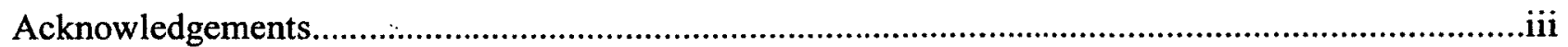

List of Tables and Figures........................................................................................................

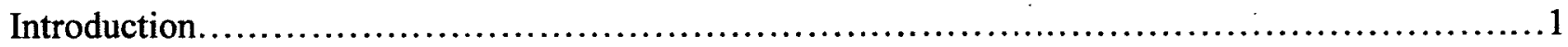

Deinstitutionalization and Criminalization.........................................2

Mental Health Courts..............................................................

Youth Mental Health Courts.................................................11

Mental Health Court Concerns....................................................13

Effectiveness of Adult and Youth Mental Health Courts................................15

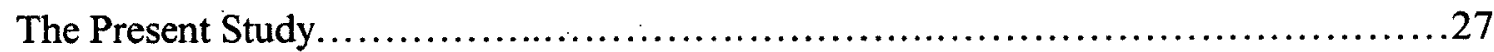

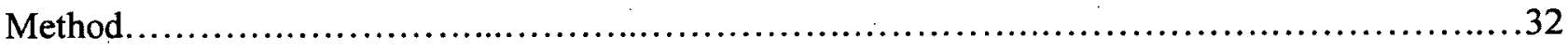

Study Inclusion Criteria................................................... 32

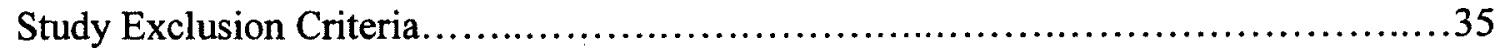

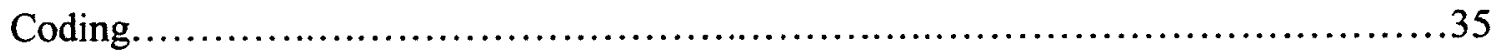

Statistical Analysis.........................................................46

Heterogeneity Across Studies..................................................47

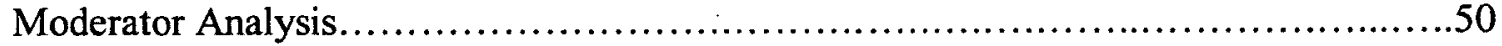

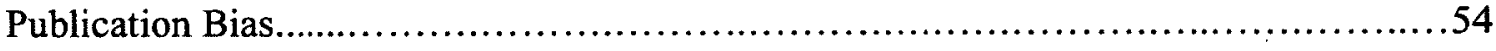

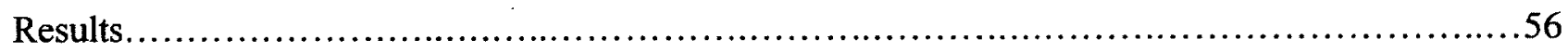

Criminal Offences and Mental Health Courts.......................................56

Recidivism Outcomes for Mental Health Court and Comparison Samples..............68

Clinical Outcomes for Mental Health Court and Comparison Samples.................77

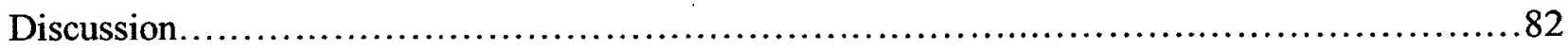

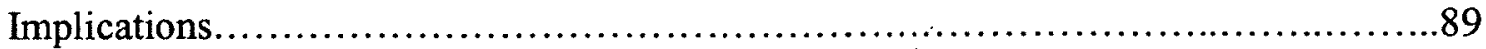

Limitations and Future Directions...........................................92

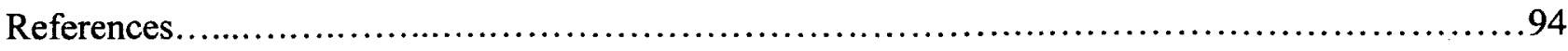

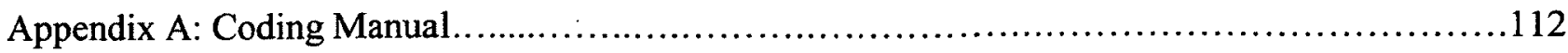


MENTAL HEALTH COURTS: META-ANALYTIC REVIEWS

List of Tables and Figures.

Table 1. Characteristics of Studies $(N=18)$ Included in the Meta-Analytic Reviews.

Table 2. Mental Health Court Participant Characteristics by Study and Mental Health Court

Site. .38

Table 3. Mental Health Court Participant Mental Health Diagnoses by Study and Mental Health

Court Site

Table 4. Study Characteristics by Mental Health Court Site and Study........................42

Table 5. Sample Sizes and Effect Sizes for the First Meta-Analytic Review........................58

Table 6. Results of the Meta-Analytic Reviews.................................................................62

Table 7. Moderator Results for Criminal Offences Based on Publication Status of Study, and

Mental Health Court Accepted Index Offences...............................................................67

Table 8. Study Sample Sizes and Effect Sizes for the Second Meta-Analytic Review..................70

Table 9. Moderator Results for Recidivism Based on Publication Status of Study, and Mental

Health Court Accepted Index Offence....................................................

Table 10. Study Sample Sizes and Effect Sizes for the Third Meta-Analytic Review $(\mathrm{N}=5) \ldots \ldots . .78$

Figure 1. Meta-analytic results for the single group meta-analysis of criminal offence outcomes.

Figure 2. Meta-analytic results for the between group meta-analysis of recidivism outcomes.........74

Figure 3. Meta-analytic results for the between group meta-analysis of clinical outcomes 
Meta-Analytic Reviews on the Efficacy of Adult and Youth Mental Health Courts

Over the past decade mental health issues have become the focus of deep public concern. Globally it has been estimated that mental health and behavioural issues affect over 450 million people (World Health Organization [WHO], 2003). Their pervasiveness, gravity, and potential to devastate lives have contributed to the development of Mental Health Courts (MHC) across Canada. To date, there are a number of MHCs in Canada and a plethora of MHCs have been established in the United States (U.S.). In the wake of the path forged by Drug Treatment Courts (DTC), MHCs have emerged as a promising alternative to the traditional avenues of criminal justice across both Canada and the U.S. These programs represent a transition from the criminalization of mental illness to a therapeutic framework for the management of those afflicted with mental health problems. Therapeutic jurisprudence is the concept that forms the basis for this problem-solving court model.

By merging criminal law with key aspects of the social sciences, MHCs represent an interdisciplinary approach to addressing criminality and important health issues. In addition to claims of reduced recidivism, MHCs appear to offer an extremely cost effective manner of implementation; the attractiveness, popularity, and continuing development of MHCs stem from these combined purported benefits (Palermo, 2010; Schneider, 2010). In order to empirically determine the true value of MHCs, a body of emerging research asks the question of how effective these programs are. The purpose of the present study was to conduct a quantitative review of the $\mathrm{MHC}$ literature in order to evaluate the relationship between MHC participation and rehabilitation.

In attempt to offer better therapeutic care to mentally ill prison inmates and reduce the large proportion of prisoners afflicted with mental illness in the Broward County Jail, the 
U.S. established the first adult MHC in Broward County, Florida in June of 1997 (Petrila, Poythress, McGaha, \& Boothroyd, 2001). By 2008 there were approximately 175 fully functioning adult MHCs in the U.S. and as of 2012, The Council of State Governments Justice Center (2012) estimates there are close to 300 (Schwartz, 2008). In Canada, there are several adult MHCs across the country, with at least four in the province of Ontario alone. Canada's first MHC was established in Toronto in May of 2008 and is the only MHC in Canada which hears cases on a consistent full-time basis (Schneider, Bloom, \& Heerema, 2007; Slinger \& Roesch, 2010). The U.S. opened its first youth MHC in Santa Clara County, California, in early 2001 in response to the growing need of appropriate mental health treatment for young offenders. Canada opened its first youth MHC in Ottawa, Ontario in 2008 (Scott, 2008). To date, there are greater than 40 youth MHCs in the U.S. and at least two in Canada (National Center for Youth Law, 2011).

\section{Deinstitutionalization and Criminalization}

Commencing in the $1960 \mathrm{~s}$, various social, financial, and scientific factors coalesced to produce a movement that resulted in drastic reductions in the services available to the mentally ill. The average length of stay in psychiatric hospital decreased from 421 days in 1969 to 189 days by 1978 (Kiesler, 1982).. Similarly, the number of available public psychiatric hospital beds declined; by $2005,95 \%$ of the hospital beds once available for psychiatric patients in 1955 had ceased to exist (Torrey et al., 2008). One of the driving forces behind this shift was the introduction of the first successful antipsychotic medication (Chlorpromazine) which made it possible for schizophrenic patients to effectively manage symptoms (Torrey, Entsminger, Geller, Stanley, \& Jaffe, 2008). The success of chlorpromazine represented a milestone in the understanding of the intricate link between 
mental illness and brain mechanisms such as neurotransmission (Rosenbloom, 2012). The management of symptoms with this medication enabled psychiatric patients to lead more stable lives thus psychiatric facilities were able to release those patients back into the community (Rosenbloom, 2012).

Second, the financial responsibility of mental health care was shifted from the individual states to the federal government (Markowitz, 2006). With this financial shift came hospital budget cuts which lead to the decreased number of available hospital beds in state psychiatric facilities along with the creation of federal financial aid programs for mental illness (e.g., Medicare, Medicaid, Social Security Disability Insurance, and Supplemental Security Income; Koyanagi, 2007; Markowitz, 2006; Torrey et al., 2008). Unfortunately the vast majority of patients in state psychiatric hospitals were not able to receive aid from these federal mental health care programs, leaving the individual hospitals to carry the financial burden (Torrey et al., 2008). This increased fiscal responsibility produced an incentive for state psychiatric facilities to reduce their number of patients (Torrey et al., 2008). Third, the rise of a liberation group in the 1960 s aimed to ensure that the grounds for forced psychiatric hospitalization were more stringent (Fisher, Silver \& Wolff, 2006; Torrey et al., 2008). The liberation group's movement eventually lead to the implementation of stricter regulations surrounding involuntary psychiatric commitment, which contributed to the decreased number of state psychiatric patients (Torrey et al., 2008). The tightening of involuntary commitment regulations meant that psychiatric commitment was considered a viable option only for those with a mental illness who are a threat to themselves and others (Borzecki \& Wormith, 1985). The majority of the responsibility of long-term care for persons with mental illnesses was eventually transferred from state/ county hospitals to community health centers. Those 
patients who were discharged from state psychiatric hospitals went back into the community without adequate mental health and support services set up to aid them in making a fluid transition (Lurigio, 2001; Sealy \& Whitehead, 2004; Slate, 2003). For some this led to a difficulty in making a healthy adjustment. At this time there was an increase in the number of mentally ill persons being attended to in hospital emergency rooms (Torrey et al., 2008) Many became homeless and unintentionally contributed to a drastic spike in prison populations (Butterfield, 1998; Ormston, 2010; Torrey et al., 2008). It has been well established that persons with mental illness are at an increased risk for coming into conflict with the law (Redlich, Steadman, Monahan, Robbins, \& Petrila, 2006).

Multiple researchers have shown that there is a large proportion of adult and young offenders in the criminal justice system with a serious mental illness (Arredondo et al., 2001; Callahan, Cocozza, Steadman, \& Tillman, 2012; Grudzinskas et al., 2005; Redlich et al., 2006; Redlich, Steadman, Callahan, Robbins, Vessilinov, \& Özdogru, 2010; Sarteschi, Vaughn, \& Kim, 2011; Slate, 2003; Teplin, 1990; Timmons-Mitchell, Brown, Schulz, Webster, Underwood, \& Semple, 1997; Torrey, 1995). According to the Standing Senate Committee on Social Affairs, Science and Technology (2006), the number of Canadian federal inmates incarcerated in 2004 with a mental illness had increased by $60 \%$ since 1967 . The same committee reported that, by including substance abuse, the prevalence of mental health issues in the federal prison population in 2004 compared to 1967 rose by an astounding $84 \%$ (Standing Senate Committee on Social Affairs, Science and Technology, 2006). Incarcerated offenders are more likely to experience psychosis, major depression and have higher rates of antisocial personality disorder (Fazel \& Danesh, 2002). Another concern stemming from the deinstitutionalization movement is that prisons are widely 
known to exacerbate psychiatric symptoms, and inmates with mental health issues are at increased risk for suicide and for being victimized by other inmates (Stone, 1997; Slate, 2003). For a large proportion of the mentally ill the criminal justice system is the de facto mental health care system (Goss, 2008). At times North American prisons have been found to house more inmates than nearby psychiatric facilities (Torrey, 1995). For many, the sole access point to much needed mental health treatment is via the police and subsequently the legal system. Hence, this well established phenomenon has been dubbed the criminalization of the mentally ill.

\section{Mental Health Courts}

In an effort to combine the multiple needs of mentally ill offenders, MHCs combine therapeutic treatment methods and criminal justice case processing with a nonadversarial team co-operative approach (Jensen et al., 2007; Redlich et al., 2006). A single docket criminal court for persons with mental illness, MHCs aim to reduce the number of mentally ill offenders in contact with the criminal justice system (Redlich et al., 2006). Simultaneously, MHCs strive to increase access to mental health services for those afflicted, and enhance public safety (Tyuse \& Linhorst, 2005). While not the acute target of MHCs, a broader goal is to decriminalize the mentally ill and reduce the stigma associated with mental illness. Despite this lofty goal, some researchers believe that MHCs are doing quite the contrary. Kaiser (2010) and Watson, Luchins, Hanrahan, Heyrman, and Lurigio (2000) claim that MHCs are

further criminalizing the mentally ill and contributing to the stigmatization of mental illness. It is becoming increasingly difficult for persons with mental illness to receive community based treatment without having to enter the criminal justice system no matter whether it is via the traditional criminal justice system or the problem-solving courts. At present, we are still not dealing with the main problem that led to the increasing number of mentally ill offenders in 
the criminal justice system: the lack of adequate community based treatment and resources. Those who receive support services (e.g., housing aid) and mental health treatment are often those who have come into conflict with the law and subsequently gain access to desired resources:

MHCs are a form of judicially mandated treatment where the judge overseeing that particular court will monitor the progress of each offender (Mason, 2005; Redlich et al., 2006). The mental health court team collaboratively develop participant specific treatment plans and co- ordinate access to care (Schneider, 2008; Slinger \& Roesch, 2010). This team is made up of the judge overseeing that particular MHC, defence counsel, prosecution, case managers/workers, and mental health treatment providers (e.g., psychologists, psychiatrists) (Schneider, 2008; Slinger \& Roesch, 2010). With a multifaceted team treatment regimens can be of many forms and can include options other than medication (Schneider, 2008). Furthermore, participants may receive help with finding housing, financial management, employment and education. Since each MHC varies in structure, some courts may have different professionals within their team. The team is actively engaged in the offender's treatment throughout their time in the MHC. The court will develop rewards for positive behaviour and sanctions or reprimands for negative behaviour for each offender reporting to the court that day (Slinger \& Roesch, 2010; Steadman et al., 2001). The judge will deliver their reprimand or rewards directly to each participant when they attend their status review hearing.

This increased dialogue and relationship with the bench is believed to increase participant's perceptions of procedural justice (Wales, Hiday, \& Ray, 2010). An increase in a person's perception of procedural justice is believed to increase their view of the court as legitimate in their decision making and as procedurally fair (Wales et al., 2010). As a result, 
participants will presumably be more likely to comply with their treatment regimen and this increased compliance is expected to be linked to a reduction in recidivism (Wales et al., 2010). The aforementioned link has been supported by research in the area of policing, legitimacy, and procedural fairness. Perceptions of legitimacy have been shown to be related to increased co- operation with police and procedurally just police behaviour has been shown to be the primary precursor to beliefs of legitimacy (Sunshine \& Tyler, 2003; Tyler \& Fagan, 2008).

The MHC involves intensive participation on behalf of the offender. They are required to attend multiple court sessions, which could be weekly, biweekly, monthly or every few months. Some researchers have found that status review hearings are sometimes held as often as four times a week to only a handful of times a year (Redlich et al., 2006). It is not uncommon for offenders to be subject to drug testing and they are required to attend ongoing rigorous treatment programs (Behnken, Arredondo, \& Packman, 2009). Initially most offenders report to the court at frequent intervals and, as they progress, the frequency with which they have to report to the court decreases provided they are meeting certain expectations such as demonstrating good behaviour. During a status review hearing, if the offender has been compliant with treatment and court orders it is not uncommon for the judge and courtroom to applaud the offender for their hard work (Redlich et al., 2005).

In Canada, in order to gain entrance to the MHC, the Crown Prosecutor has to determine that the root cause of the criminal behaviour was a mental illness and that the individual is an appropriate candidate for diversion (Hartford et al., 2004). In the case of MHCs, the Crown Prosecutor has to determine that the candidate is appropriate for MHC specific diversion. This requirement has been set forth by the Crown Policy Manual for 
Diversion of Mentally Disordered Offenders (Ontario Ministry of the Attorney General, 1995). It is important to note that the development of MHCs across Canada has not required the creation of new legislation as they are considered an alternative form of court diversion which is permitted under the Canadian Criminal Code (as cited in Hartford et al., 2004; Hartford et al., 2004). Also in Canada, the accused has to meet the specific criteria set out by the MHC and has to agree to participate in order to be eligible for the MHC. For example, at the Toronto Adult Mental Health Court, offenders who have committed a Class III offence (see the Criminal Code for further elaboration) such as murder, manslaughter or infanticide, are not eligible to participate in a MHC. In Ontario, diversion is mainly offered as an option for offenders who have committed a Class I offence and sometimes a Class $\Pi$ offence as long as it was not a commission of a violent act (Hartford et al., 2004). Ontario offenders with a mental illness who have previously been diverted or have a criminal history are not necessarily excluded from participating in diversionary measures for the most recent criminal act and this is also the case for a number of MHCs across the U.S. (Hartford et al., 2004).

Depending on the specific $\mathrm{MHC}$, the accused may or may not be required to enter a guilty plea prior to commencing the treatment program (Redlich et al., 2005). The majority of American MHCs are pre-plea (Slinger \& Roesch, 2010). Some American MHCs and the Toronto, Ontario MHC divert offenders pre-adjudication (Schneider et al., 2007; Slinger \& Roesch, 2010). Regarding the pre-plea system, offenders generally have a certain time period (usually 30 days).to revoke that plea and re-enter the traditional justice system where they would likely face a sentence of incarceration.

For the most part, individuals who are eligible to participate in a MHC have been charged with a nonviolent offence (Redlich et al., 2005). MHCs in the U.S. are starting to 
change their practices and accept those who have committed a felony, depending on the circumstances of the crime, and not just offenders who have committed a misdemeanour (Redlich et al., 2005). Newer MHCs which accept offenders who have committed a felony are called second-generation MHCs (Redlich et al., 2005). MHCs, like DTCs, are judicially mandated treatment programs that can eliminate any possibility of jail time and have charges stayed, withdrawn or reduced (Schneider, 2008; Slinger \& Roesch, 2010; Werb, Elliott, Fischer, Wood, Montaner, \& Kerr, 2007). From an offender standpoint, the possibility of having charges stayed, dismissed or reduced may make MHCs a highly attractive option.

While some variation exists based on differences in location and program components, a review of the literature provides a consistent portrait of the average MHC participant; this individual is typically a Caucasian male in his mid-thirties (Boothroyd, Mercado, Poythress, Christy, \& Petrila, 2005; Christy, Poythress, Boothroyd, Petrila, \& Mehra, 2005; Cosden et al., 2005; McNiel \& Binder, 2007; Steadman et al., 2005; Trupin \& Richards, 2003). In terms of diagnoses, psychotic and affective (mood) disorders are those most frequently represented (Lindberg, 2009; Palermo, 2010; Trupin \& Richards, 2003; Steadman et al., 2005).

Schizophrenia is often the most common psychotic disorder, bipolar disorder and depression the common affective ailments (Palermo, 2010; Steadman et al., 2005). Finally, substance abuse and homelessness are prevalent problems in the MHC population. In a study of two Nevada MHCs, Palermo (2010) found that $85 \%$ of MHC participants have substance abuse disorders. When evaluating the San Francisco MHC, McNiel \& Binder (2007) found that 34\% of participants were homeless.

In Canada, the primary focus of MHCs has not necessarily been on helping all persons with mental health issues who have come into contact with the law, but has been focused on 
dealing with those who are deemed unfit to stand trial (Schneider, 2008). In these cases, participation on behalf of the offender is not voluntary and the offender does not proceed though the MHC system. Rather, in these cases the offender only comes to the MHC for a fitness assessment. For offenders proceeding through the $\mathrm{MHC}$, and depending on both the preferred treatment method of the particular court and the offender's needs, participants will have tailored treatment programs which will be dependent on the resources available to the court. The offender at any point can withdraw voluntarily from the program and be sent back through the traditional criminal justice system or they could be expelled from the MHC program. As will be discussed in the coming pages, some court participants are unaware of this voluntariness. After certain treatment and other criteria (as determined by each specific court) has been satisfied, the offender is eligible for graduation from the program.

Problem-solving courts have a theoretical foundation based upon the interdisciplinary approach of therapeutic jurisprudence. Therapeutic jurisprudence may be defined as "the use of social science [specifically psychology and the behavioural sciences] to study the extent to which a legal rule or practice promotes the psychological and physical well-being of the people it affects" (Hora, Schma, \& Rosenthal, 1999; La Prairie, Gliksman, Erickson, Wall, NewtonTaylor, 2002; Mason, 2005). Therapeutic Jurisprudence seeks to explore how law functions to cause therapeutic or antitherapeutic effects, and aims to reduce the latter and increase the former without jeopardizing values integral to our justice system (Winick, 1997). The therapeutic jurisprudence court model is best described as a mechanism wherein the legal system and mental health care system function as one; together they utilize the judiciary as a means to encourage better psychosocial functioning and adaptive health behaviours (Belenko, 1998). 


\section{Youth Mental Health Courts}

Adolescence (approximately ages 10 to 17 ) is prominently characterized by ongoing psychosocial development where many cognitive and biological changes are occurring simultaneously (Paikoff \& Brooks-Gunn, 1991; Paus, 2005; Steinberg \& Silverberg, 1986; Yurgelun-Todd, 2007). It is also well known as a turbulent stage in life for most youth (Tarter, 2002; Eccles, Midgley, Wigfied, Buchanan, Reuman, Flanagan, \& Mac Iver, 1993). Although adolescence is not equally tumultuous for all teens, it is generally agreed that most encounter some difficulty transitioning in and out of this period of life (Gutman \& Eccles, 2007; Eccles et al., 1993). The vast majority of individuals (75\%) who become afflicted with a mental illness will experience its onset prior to the age of 24 (as cited in Kutcher \& McDougall, 2001). Despite widespread efforts to provide adequate access to mental health care for those youth who are in need, a mere quarter of these youth receive treatment (Ormston, 2010).

As is true for adults, the lack of available mental health care resources also means an large portion of youth go untreated. The availability of mental health care for children and youth has declined while nations have strived to cut health care costs, and parental benefits packages offer limited to no financial aid for costly mental health treatment (American Academy of Pediatrics, 2000). Even with established health services in a community, youth and their families often are not linked to available resources (Callahan et al., 2012). This is a concern given that early identification and treatment of mental illness, especially serious mental illness, will increase the likelihood that young mentally ill persons will be able to lead lives comprised of stability (Arredondo et al., 2001; Behnken, Arredondo, \& Packman, 2009). Early intervention also contributes to the ongoing protection of public safety (Arredondo et al., 2001; Behnken et al., 2009). 
As previously noted, a large segment of the incarcerated population suffers from mental illness. This is also true for young offenders, with some researchers documenting rates of mental illness among incarcerated youth at greater than 50\% (Kutcher \& McDougall, 2009; Cocozza \& Shufelt, 2006; National Mental Health Association, 2000; Atkins, Pumariega, Rogers, Montgomery, Nybro, Jeffers, \& Sease, 1999). Needless to say this rate of mental illness within youth criminal justice facilities is greater than that found within the population at large (Costello, 1989; Edens \& Otto, 1997). It is estimated that the prevalence of serious mental health issues in the youth criminal justice system is at least approximately $20 \%$, and likely greater (Open Society, 2000). Atkins and colleagues (1999) found that the prevalence of psychopathology in an American sample of youth (ages 13-17) either incarcerated, hospitalized (at a mental health facility), or receiving treatment at a community mental health facility was similar. While rates of mental illness for youth in criminal justice facilities have been found to be high for males and females alike, they tend to be much higher for females (84\%) than males (27\%; Timmons- Mitchell et al., 1997). The most common diagnosis of youth in the criminal justice system is conduct disorder, it is comprised of both emotional and behavioral difficulties (Edens \& Otto, 1997; Timmons-Mitchell et al., 1997).

It is well known that the vast majority of incarcerated youth with a diagnosed mental disturbance are in facilities for minor offences (Mental Health America, 2012). There is concern that, for youth who enter the criminal justice system without showing evidence of a health concern (whether it be mental or behavioural), one may begin to present as having a health issue upon entering the justice system because time spent in a criminal justice environment has triggered the health problem (Goldstrom et al., 2000). Researchers Behnken et al. (2009) mention in their pre-post study of criminal offence history in a juvenile MHC 
that, in areas of the U.S., parents strive to have their child come into contact with the criminal justice system in attempt to obtain much needed mental health services. The inability of the criminal justice and mental health systems to independently aid the large proportion of persons with mental illness has led to the joining of the two systems via the development of adult and subsequently youth $\mathrm{MHCs}$.

As with the Canadian adult MHCs, no new legislation had to be developed for the establishment of youth MHCs in Canada. Youth MHCs are a form of diversion for youth under 18 years of age. Youths who are eligible for MHC diversion have been charged with a criminal offence and find themselves under the jurisdiction of the Youth Criminal Justice Act (Mitchell, 2008). An underlying mental illness must be the primary reason for the commission of the offence for which the diversionary measures are being considered (Mitchell, 2008). Youth MHCs appear to be identical to adult MHCs but are tailored to the different needs of youth offenders and can include more participation on behalf of the family than in adult MHCs. For example, participation in the youth MHC in Santa Clara, California can involve family therapy (Behnken, Arredondo, \& Packman, 2009).

\section{Mental Health Court Concerns}

Given their nature, nascence, and various (and sometimes conflicting) goals, some fairly weighted concerns regarding MHCs have been identified. one such issue of concern is the concept of judicially mandated treatment for mental illness, not to mention the use of legal sanctions to promote treatment compliance. In the evaluative literature of MHCs it is commonly reported that participation was voluntary, or that participants had to consent to treatment. For example, in the evaluation of the Clark County MHC, Herinckx, Swart, Ama, Dolezal, and King (2005) specifically mention that participants had to consent to participation in court. That being said there is no mention of the actual state or competence of each 
participant when they consented to participation. Morin (2004) reported that participation in the Hennepin County MHC in Minnesota was presumed to be voluntary and that it was assumed that participants who opted into the MHC program were competent. Further, judicial supervision of treatment adherence is a (common) feature of MHCs. This feature may be perceived as a conflict of interest between the health care system and the adversarial system which are based upon well- established competing philosophical values (crime and punishment versus offender rehabilitation; Sarteschi, 2009).

Morin (2004) reported that participants of the Hennepin County MHC who failed to follow the treatment agreement could be incarcerated until the participant was willing to comply with the treatment order, or dismissal from the program. In their evaluation of the King County MHC in Washington, Trupin, Richards, Lucenko, and Wood (2000) mention that participants of the MHC experience much greater supervision than offenders in the traditional court system. At least for the King County MHC this is because there are roughly 150 to 160 less clients assigned to the MHC probation officer than the traditional court probation officers (Trupin et al., 2000).

The use of mandatory minimum treatment compliance regulations in MHC programs should also be questioned. Mandatory minimum treatment compliance refers to specific lengths of time a MHC participant must comply with treatment orders in order to graduate from the MHC program. A MHC located in the Bronx, New York has mandatory minimum treatment lengths of 6 months, and 18-24 months for misdemeanour and felony offences respectively (Rossman, Willison, Mallik-Kane, Kim, Debus-Sherrill, \& Downey, 2012). Another MHC located in Brooklyn, New York has minimum treatment lengths of 12 months for misdemeanours, and either 12-18 or 18-24 months depending on the type of felony 
(Rossman et al., 2012). In their preliminary observation report of the Broward County MHC evaluation, Petrila et al. (2001) mention that persons participating in a MHC may spend more time under its jurisdiction than if their case had been processed via a misdemeanour court. The possibility that this aspect of the MHC program is an infringement upon participants' freedom should be explored.

The issue of voluntariness in MHCs has been of great concern over the past few years. A study conducted by Redlich, Hoover, Summers, and Steadman (2010) demonstrated that most participants in the Brooklyn and Washoe County MHCs indicated that they made their own decision to enroll in their respective MHC but that more than half of the same participants also indicated that, prior to their enrollment in the court, they were not informed that the decision to participate was voluntary. Boothroyd, Poythress, McGaha, and Petrila (2003) found that just over half (53.7\%) of Broward County MHC participants knew their participation was voluntary pre- enrolment.

\section{Effectiveness of Adult and Youth Mental Health Courts}

The MHC literature has been accumulating over the last decade with most of the literature dedicated towards chronicling the development, functioning, and the characteristics of each MHC population. Technical reports of the American MHCs are on the rise and there is a developing body of research on how to best structure and evaluate MHCs, in addition to some research on lessons learned from previous MHC evaluations. MHCs pose difficult, and sometimes insurmountable challenges when trying to conduct sound research. For example, randomization is often not conceivable due to proverbial administrative red tape and ethical concerns. In order to conduct research in a MHC environment it is necessary to obtain permission from a variety of required sources, in Canada this includes the Crown, and this is sometimes not possible. Practically speaking it can also be quite time consuming and difficult 
to coordinate a randomized controlled study in a MHC and traditional court system with large caseloads. It can be difficult to locate and conduct follow-up assessments with offender populations. Also, to some, withholding what may be considered a more superior treatment is a very salient ethical concern. Without true randomization one cannot decisively determine whether or not the particular treatment the offender was exposed to was a direct cause of any changes in recidivism or any outcome of interest (Sibbald, 1998).

While the true experimental design is difficult to implement in evaluation studies of MHCs, it is not impossible as Bess (2004) and Cosden et al. (2004) have demonstrated. With funding from the California Board of Corrections, Mentally Ill Offender Crime Reduction Act, Cosden et al. (2004) randomized 235 participants to receive either treatment as usual or processing through the Santa Barbara County, CA, Mental Health Treatment Court (MHTC; Cosden et al., 2004). Treatment as usual was characterized by traditional adversarial justice system case processing with a referral to the county mental health services (Cosden et al., 2004). The Santa Barbara MHTC is characterized by intensive case management where offenders receive assertive community treatment (Cosden et al., 2004; Cosden et al., 2005). Cosden et al. (2005) found that while participants of the MHTC had a greater decrease in the average number of days spent in jail, the difference was not statistically supported. However, this is not to say that the reduction in jail days was not of importance to the legal community. Moreover, participation in the MHTC appeared to boost subsequent outcomes in other areas. Approximately $67 \%(N=157)$ of the overall sample had follow-up assessment data for each of the five time points on psychosocial measures, which were assessed using Lehman's (1988) Quality of Life scale (QOL; short form) and Global Assessment of Functioning (GAF) scores among others. The GAF measure is a clinician rating system for a 
person's overall social, occupational, and psychological functioning (Aas, 2011). Cosden et al. (2005) found that psychosocial functioning increased in both the MHTC and TAU samples, but the MHTC sample showed greater improvements.

The other experimental study that has been conducted with a MHC sample was carried out by Bess (2004) and associates. The Bess (2004) study was part of a three year pilot project in Butte County, California, which was initiated as a response to the Mentally Ill Offender Crime Reduction Project. A hope of the pilot project was to eventually establish a MHC in Butte County (Bess, 2004). Participants were randomized to receive either the community's standard of care (treatment as usual) or enhanced treatment which included processing via the pilot MHC (Bess, 2004). The final sample sizes were 50 and 41, for the enhanced treatment and treatment as usual groups, respectively (Bess, 2004). Both the enhanced treatment and treatment as usual groups had reductions in number of bookings and convictions from 0 to 12 months prior to program participation in comparison to 6 months following program exit (Bess, 2004). Only the enhanced treatment group, however, exhibited a reduction in number of days spent in jail for the aforementioned time periods (Bess, 2004). Further, the enhanced treatment group had greater reductions in bookings, convictions, and number of days spent in jail then the treatment as usual group in the six months after program exit (Bess, 2004). For most of the measures of psychosocial functioning (e.g., GAP, QOL, Behavior and Symptom Identification Scale [BASIS-32]) the enhanced treatment group had greater improvements than the treatment as usual group. The BASIS-32 is a 32-item self-report measure of symptoms and problems and can be used to assess change over the course of time spent in treatment (McLean Hospital, 2012).

Unfortunately a limitation of this study was that the treatment as usual sample was 
referred to a variety of other courts after study enrollment, one of which was a DTC (Bess, 2004). In this study, treatment as usual could have consisted of a variety of different paths through the criminal justice system and so members of the comparison sample were not necessarily exposed to the same conditions. With the treatment as usual group having varying degrees of overall care, one cannot infer that participation in the enhanced treatment group was superior to each of the independent routes through the criminal justice system that the treatment as usual group took. Rather, what we can infer is that enhanced treatment was more effective than the treatment as usual group as a whole, while ignoring treatment differences within this group.

MHCs have been shown to be related to reduced drug abuse, improvements in offenders overall levels of functioning, increased skill training, and follow-up care after successful graduation (Tyuse \& Linhorst, 2005). Using a quasi-experimental design, Trupin and Richards (2003) compared offenders who opted into a MHC to those who opted out, in order to investigate the effectiveness of two MHCs located in Seattle: Seattle and King County MHCs. According to their findings the Seattle MHC participants exhibited reduced recidivism following MHC participation, and partaking in the MHC increased offender's alignment with opportunities for treatment (Trupin \& Richards, 2003). Participants of the King.County MHC had increased levels of psychosocial functioning-as measured by GAF scores-following MHC involvement (Trupin \& Richards, 2003).

Some studies have also suggested that MHC completion rates are high. For example, $90 \%$ of the adults who enter the Saint John, New Brunswick MHC graduate from the program (Saint John Mental Health Court, 2009). The Oklahoma Department of Mental Health and Substance Abuse Services (2012) reported that in a sample of MHC graduates, unemployment decreased by $77 \%$ from MHC enrollment to graduation. For the same 
sample, number of days spent as an inpatient decreased by $25 \%$ from one year preenrollment to one year post (Oklahoma Department of Mental Health and Substance Abuse Services, 2012). Researchers McNiel and Binder (2007) examined the success rate of 170 participants diverted from the San Francisco jail to the San Francisco Mental Health Court, with a sample of undiverted offenders booked into the San Francisco jail. Their results supported the notion that that particular mental health court is related to reductions in recidivism for offenders who committed nonviolent misdemeanours or more serious violent offences (McNiel \& Binder, 2007). This reduction in recidivism was observed both for offenders who failed to graduate from the MHC and those who graduated (McNiel \& Binder, 2007). A number of other studies have reported similar findings (Herinckx, Swart, Ama, Dolezal, \& King, 2005).

The reduction in criminal acts may be evidence that successful graduation from a MHC is not solely necessary in order for the court to be of benefit. However, it has been found that graduation from a MHC is more likely to be associated with lower rearrest rates and a greater reduction in recidivism than for those who opted out (Hiday \& Ray, 2010). Hiday and Ray (2010) conducted a single site study of a MHC located in North Carolina. The researchers examined number of arrests two years prior to $\mathrm{MHC}$ involvement and two years following MHC exit in a sample of 99 participants who left the MHC in 2005 (Hiday \& Ray, 2010). Of the 60 participants who successfully completed the program $28 \%$ were rearrested following their MHC exit; this number of arrests significantly reduced from prior to entering the program $(M=3.18, S D=2.67)$ to two years after exiting $(M=1.02, S D=2.28$; Hiday $\&$ Ray, 2010$)$. Of those who were expelled or opted out from the $\mathrm{MHC}, 81 \%$ and $63 \%$ respectively were rearrested (Hiday \& Ray, 2010). It is important to note that because the structure of MHCs 
vary from one state to another, or between provinces, the generalizability of the findings of this study depend on how much other MHCs resemble the structure of this particular court (McNiel \& Binder, 2007).

Similar to the adult MHC research, studies that have been conducted on youth MHCs have demonstrated that they are related to reductions in recidivism (Behnken et al., 2009; Makany-Rivera, 2010; National Center for Youth Law, 2011). In a pre-post study of the initial three years of the Alameda County Juvenile Collaborative Court (ACJC) in California, the National Center for Youth Law (2011) found that, for a sample of 23 youth, they spent less days in custody, the number of youth detained decreased by almost half, and probation and new law violations both decreased in the 12 months following MHC participation. The number of days spent in detention decreased from 2,287 in the 12 months preceding ACJC participation to 852 days in the 12 months following ACJC participation (National Center for Youth Law). The same study found a decrease in the number of youth who experienced a psychiatric crisis during and after involvement $(N=5)$ than before involvement with the ACJC $(N=10 ;$ National Center for Youth Law, 2011). Unfortunately the conclusions which may be drawn from this report are limited because of the small sample sizes, the lack of descriptive statistics and statistical analysis, and the lack of a comparison sample.

The Court for the Individualized Treatment of Adolescents (CITA) in Santa Clara, California, began in 2001 as a pilot project for the treatment of mentally ill young offenders. An empirical evaluation of the CITA program by Behnken, Arredondo, and Packman (2009) found a statistically significant change in mean number of arrests from 18 months before enrollment in the MHC $(M=2.98)$ to 23 months following MHC enrollment for 64 CITA graduates $(M=1.14$; Behnken et al., 2009). Participants of CITA were mostly males (67.42\%) 
aged 15 years old, diagnosed with Attention Deficit Hyperactivity Disorder (60.15\%; Behnken et al., 2009). More than a third of CITA clients were diagnosed with Bipolar Disorder (38.35\%), Developmental Disorders (38.4\%), and Major Depression (34.59\%; Behnken et al., 2009).

In a study of the Travis County, Texas, Collaborative Opportunities for Positive Experiences Program (COPE); Makany-Rivera (2010) measured recidivism as number of new arrests and re-referrals to the program within one year of program graduation. In 2008 , the COPE program had a graduation rate of $69 \%$ and a recidivism rate of $34.8 \%$ (Makany-Rivera, 2010). Without having a similar comparison group of young offenders who received an alternate form of care, it is impossible to know whether the reported recidivism rate supports the relationship between $\mathrm{MHC}$ participation and reductions in criminal offences. The El Paso County Special Needs Diversionary Program (SNDP) in Texas had low rates of participant recidivism, as measured by re-offending, in $2008(16 \%), 2009(17 \%)$, and $2010(16 \%$; Makany-Rivera, 2010). The same study reported that the El Paso County Juvenile Probation Department had a recidivism rate of approximately $17 \%$ over the same three year time period, with the recidivism rates of the SNDP and the probation department being almost identical (Makany-Rivera, 2010). The same MHC program had participant success rates ranging from $57.14 \%$ to $88 \%$ between 2007 and 2010 (Makany-Rivera, 2010). The early results from quasiexperimental and experimental studies of American MHCs offer support of their ability to reduce future run-ins with the law. Unfortunately the youth literature is mainly comprised of single group studies which at this time do not permit a similar conclusion.

A meta-analysis conducted by Sarteschi et al. (2011) examined clinical and recidivism outcomes of the adult MHC literature available up until July 2009 for programs in the United 
States. It was determined that 15 studies could contribute a recidivism outcome to their metaanalytic review. Results from this study showed that MHC participation was related to a reduction in recidivism (Hedge's $g=-.54$ ). Eight studies reported clinical outcomes which could contribute an effect size, yet due to the heterogeneity between them, the authors did not meta- analyze these outcomes (Sarteschi et al., 2011). Independently examining the outcomes, however, revealed that MHC participation is related to increases in GAF scores (Hedge's $g=-$ .69 ), as well as to a reduction in the number of days spent as an inpatient at a psychiatric facility (Hedge's $g=-2.03)$.

Another meta-analytic review of the U.S. adult MHC literature was conducted by Cross (2011) and examined available studies of MHCs up until April 2011. The Cross (2011) study was found in the present author's latest literature search. Literature searches for this study were ongoing until the beginning of the statistical analyses in order to ensure that all recent MHC studies would be included. The Cross (2011) meta-analytic reviews found 18 studies that could contribute a recidivism outcome and 5 studies that could contribute a clinical outcome. Clinical outcomes included measures of hospitalization (e.g., days and occurrences) in addition to scores on clinical assessment measures (e.g., BASIS-32 and GAF scores; Cross, 2011). The summary effect size for the recidivism review was $d=.32(\mathrm{CI}=$ $.12, .51 ; p=.000)$ and was considered a small to medium effect size; MHC participation was associated with a reduction in recidivism (Cross, 2011). Cross (2011) found no effect of MHC participation on clinical outcomes $(d=-.09 ; \mathrm{CI}=-.38, .19, p=.51)$. What is noteworthy is that the Cross (2011) clinical review reported an effect size that was in the opposite direction of what was hypothesized. While it was expected that MHC participation would be linked to better clinical results (e.g., reduced hospitalization), the Cross (2011) findings ran contrary to this hypothesis. The two noted meta-analytic reviews of the adult U.S. MHC literature provide 
positive support for the effects of MHC participation on recidivism and no support for the effect of MHC participation on clinical outcomes.

In the meta-analysis conducted by Cross (2011), the researcher elected to prioritize recidivism information measured at 12 months from enrollment into the MHC followed by recidivism measured at the end of $\mathrm{MHC}$ involvement. Given that MHCs are a form of outpatient care there is a strong possibility that $\mathrm{MHC}$ participants will be rearrested while involved in the $\mathrm{MHC}$ as treatment will not eliminate recidivism immediately but with time and treatment compliance it may reduce or eliminate the possibility of recidivism. Comparison group participants who are engaged in the traditional criminal justice system may spend a period of time in an institutional setting for the offence considered the index offence in the study in question, thereby reducing the likelihood of rearrest in the follow-up period.

Cross (2011) did not include single group studies where outcomes of interest were measured prior to MHC involvement and post treatment (pre-post design). Sarteschi et al. (2009) included single group studies yet meta-analyzed them in the same analysis as the group comparison studies. Pre-post and comparison group designs answer fundamentally different questions (e.g., did the MHC reduce the commission criminal offences versus did the MHC reduce recidivism in comparison to those processed via the traditional court system), but they are both relevant to the primary question at hand: are MHCs effective? The difference in study designs and questions in which they answer can easily be accommodated by meta- analyzing studies with a comparison group separately from those with a pre-post design in order to answer both of the above aforementioned questions. If MHCs are no better than pre-existing practices changes can be made to better direct treatment and resources. 
The Sarteschi et al. (2011) and Cross (2011) meta-analyses included studies with a dichotomous recidivism outcome as well as studies with continuous measures of recidivism. As a continuous outcome measure recidivism may be skewed. Statistically significant skew is worrisome in small samples while the degree of skew is more worrisome in larger samples (Tabachnick \& Fidell, 2007). Skew is therefore important regardless of the sample size and can affect the validity of the results of $t$-tests and Analysis of Variance. Given this concern it is most appropriate to use a dichotomous measure of recidivism but in the majority of MHC studies continuous measures of recidivism are used. This may partly be because evaluations of MHCs tend to examine how much they reduce recidivism in comparison to other forms of diversion or traditional court samples. Analyzing recidivism, as a dichotomous or continuous measure, will like pre-post versus comparison group designs, answer fundamentally different questions. Examining recidivism as a dichotomous outcome answers the question, do MHC participants recidivate? Whereas using a continuous measure of recidivism answers the question, was recidivism reduced after the intervention?

While it is possible to calculate the standardized mean difference (Cohen's $d$ ) from change values for between group comparisons, it is not possible to combine Cohen's $d$ values obtained from change values with standardized mean difference (Cohen's $d$ ) values from post scores (Cochrane Collaboration, 2002). In a between-group comparison study (e.g., MHC versus traditional court sample) Cohen's $d$ calculated from change scores would mean that the change from pre-group to post-group was taken into account for both the MHC group and comparison group. In a between-group study where only post-group scores are used, Cohen's $d$ is calculated from the difference between groups at only one time point, post-group. Both the Sarteschi et al. (2011) and Cross (2011) meta-analyses included the Trupin and Richards 
(2003) study of group comparisons between two MHCs in Seattle, with Cohen's $d$ values based on group change scores. The Trupin and Richards (2003) study was included in the same analysis as the studies which used Cohen's $d$ based on post-group scores. The Cross (2011) meta-analysis included the Boothroyd et al. (2005) study of change scores in the metaanalysis of clinical outcomes. The Boothroyd et al. (2005) study should not have been included in the analysis for the same reason as listed above for the Trupin and Richards (2003) study.

The Sarteschi et al. (2011) and Cross (2011) studies both included moderator analyses yet neither had MHC specific moderators. The moderators used in the previous meta-analyses were solely related to each study but not to MHC characteristics like the type of offences the court accepts (e.g., misdemeanor only). MHCs are known to vary widely and it is plausible that variability in clinical outcomes and rates of criminal activity can be accounted for by the different types of MHCs.

The Sarteschi et al. (2011) and Cross (2011) meta-analyses violated independence of observations. The Sarteschi et al. (2009) study did not include any “....studies that reported on (presumably) the same set of participants published by the same set of researchers." If the same set of researchers published a study in 2001 and another in 2003, only the latter study was used. Sarteschi et al. (2011) did however duplicate one MHC. The Trupin and Richards (2003) study included recidivism information from the King County MHC in Washington while the Neiswender (2005) study also studied recidivism at the King County MHC in Washington. Both of these studies were included in the Sarteschi et al. (2011) meta-analysis and used information collected on participants from an overlapping timeframe. The Cross (2011) study also used the two aforementioned studies with overlapping samples, in addition 
to including the following studies: Trupin, Richards, Wertheimer, and Bruschi (2001), Trupin and Richards (2003), Moore and Hiday (2006), Hiday and Ray (2010), McNiel and Binder (2007), Morin (2004), and Steadman et al. (2011).

The Trupin et al. (2001) study and the Trupin and Richards (2003) study shared a sample that was collected at the same date. The studies completed by Moore and Hiday (2006) and Hiday and Ray (2010) used the same MHC: the North Carolina MHC also known as the Orange County Community Resource Court. The McNiel and Binder (2007) and Steadman et al. (2011) studies used the same MHC: the San Francisco MHC also known as the Behavioral Health Court. Despite San Francisco and North Carolina MHC studies having used the same courts, the data collection dates did not overlap. In the absence of direct data collection overlap, there is still a possibility that the samples included some of the same participants. For example, there are only two years between the end and start of data collection for the Moore and Hiday (2006) and Hiday and Ray (2010) studies. The Morin (2004) study and Steadman et al. (2011) studies both used the same MHC in Hennepin County, Minneapolis. Ideally MHCs could eliminate recidivism but with the known complexities of mental illness and situational factors, it is more likely that MHCs can help reduce recidivism and improve overall wellbeing, thus it is likely that MHC participants will become re-involved with a MHC at a later date but for a different index offence. Due to the possible re-involvement of participants in a MHC there is no way to know with certainty that the studies using the same MHC have participant samples that are independent.

A number of MHC studies use multiple outcomes of the same construct, for example, the multisite study conducted by Steadman et al. (2011) measured recidivism in two ways: annualized arrest rates and average incarceration days. Analyzing the outcomes separately in 
a meta-analysis causes the studies with more outcomes to be assigned greater weight (Borenstein et al., 2009). Analyzing the outcomes separately also causes them to be treated as contributing independent information when in reality they are interdependent if the same sample was used (Borenstein et al., 2009). Not only are the outcomes interdependent, it is highly likely that these two outcomes would be positively correlated since they are measuring the same overall construct (Borenstein et al., 2009): When outcomes are positively correlated error is underestimated and the exactness of the summary effect will be overestimated consequently leading to a biased effect (Borenstein et al., 2009). In order to prevent interdependence of outcomes, Sarteschi et al. (2011) only meta-analyzed one outcome per outcome of interest (recidivism and clinical outcomes) per study. Cross (2011) priority ranked outcomes and only selected one outcome per outcome of interest (recidivism and clinical outcomes) per study. In the Cross (2011) study it was not clear whether the author priority ranked outcomes in order to prevent interdependence or if there was another rationale.

As discussed in the next section, the purpose of the current study is to build on the previous meta-analytic reviews of the adult MHC literature in addition to reviewing the youth and Canadian MHC literature. To the author's knowledge, this review of the youth and Canadian MHC literature will be the first. The information gleaned from this study will contribute to the growing body of $\mathrm{MHC}$ research and provide clarification as to whether or not MHCs, as a whole, are achieving all that they strive to.

\section{The Present Study}

Prior to MHCs becoming a permanent fixture in our society we need more rigorous research in order to establish whether they are in fact efficacious and for whom. Efficacy is a highly subjective term that is comprised of many facets. It is believed that in order to 
appropriately examine the efficacy of MHCs, clinical and offence history outcomes need to be re-examined. It is important to understand whether MHCs are effective both in the commission of criminal offences and increasing psychosocial functioning - a construct comprised of one's social, occupational/educational, and psychological attributes- - for youths and adults. In order to reliably answer the research question "are mental health courts an appropriate form of diversion?" another systematic review is required; a meta-analysis provides the means to produce research based evidence supporting or disproving the claim that MHCs are effective. As an increasingly important tool for the research community, metaanalyses have led to important research developments. One such example is in neonatal care where, in 1989, a meta-analysis found that the risk of a premature baby dying can be reduced by $30 \%$ to $50 \%$ if a steroid is administered (Goldacre, 2010). A number of individual studies had looked at the use of steroids in improving premature newborns survival rate but independently the results were inconclusive (Goldacre, 2010).

As previously mentioned there have been two meta-analyses on MHCs which both focused solely on adult MHCs in the U.S. This study will update the Sarteschi (2011) and Cross (2011) meta-analyses by including published and unpublished studies on all MHCs in North America up until May $15^{\text {th }}, 2012$. Cross (2011) indicated that she did not include studies from other countries due to differences in legal systems however given the similarities between the American and Canadian criminal systems and the identical set-up of MHCs in both Nations, this author felt that it is reasonable to include studies from both. The author is aware of some MHC evaluations that have concluded and produced reports since the Sarteschi et al. (2011) and Cross (2011) meta-analyses. For example, since the Sarteschi et al. (2009) study, prominent authors in the MHC arena Steadman et al., (2011), have completed a multisite MHC study of four San Francisco, California MHCs with outcomes of participant 
arrests and incarceration days. Since the Cross (2011) study, Rossman et al. (2012) have released a technical report of the evaluations of the Bronx and Brooklyn MHCs. The report includes recidivism rates for the two New York courts and their comparison groups.

In order to improve on the previous meta-analyses, this author strived to address their limitations in the present meta-analytic reviews. Some of the ways in which limitations were addressed are as follows. First, in order to have a more fair and accurate reflection of recidivism, in this study the recidivism measure with the longest follow-up period was prioritized. Another reason supporting this decision is that participants who partake in the MHC may experience greater reduced short-term recidivism but with a longer follow-up period there may be no difference between groups. In order to assess the true long-term benefits of MHCs one must examine the measures with the longest follow-up periods. Second, instead of meta-analyzing continuous and dichotomous outcomes in one review, the current author opted to exclude dichotomous outcomes because the majority of MHC evaluations only investigated continuous outcomes. Third, MHCs are known to vary widely and it is hypothesized that variability in clinical outcomes and rates of criminal activity will be accounted for by the different types of MHCs. In order to investigate this hypothesis the current study will use MHC site specific characteristics such as offence type and dual diagnosis requirements as moderators.

Fourth, change scores calculated from comparison group studies cannot be meta-analyzed along with change scores from single group studies. In order to avoid this problem, the current author excluded the comparison group effect sizes presented in the published Trupin and Richards (2003) paper and instead used the available results (Means and Standard Deviations) reported in the original technical reports. Single group (pre-post) results from the Trupin and Richards (2003) study were not excluded from the current study as their effect size was valid. Fifth, multiple measures of the same construct in a study causes the data structure to be 
considered complex, but Comprehensive Meta-Analysis (CMA) is equipped to handle complex data structures. Using CMA this study will prevent interdependence of outcomes, the loss of important information, and assigning more weight to studies with more outcomes by creating a composite variable. A composite variable becomes the new unit of analysis (per study) and is the mean of the outcomes that measure the construct of interest (Borenstein et al., 2009).

The current study is composed of three meta-analyses: One examining the singlegroup (pre-post) criminal offence research on adult and youth MHCs; the second examining the available experimental and quasi-experimental recidivism research on adult and youth MHCs; and the third examining the experimental and quasi-experimental clinical research on adult MHCs. The present study seeks to answer the following primary questions:

1. Do MHC participants experience reduced rates of criminal offences post-MHC involvement?

2. Do $\mathrm{MHC}$ participants experience less recidivism post-MHC involvement than similar comparison groups or those who proceed through the traditional criminal justice system?

3. Do MHC participants experience improvements in clinical outcomes, as measured by measures of psychosocial functioning and rates of hospitalization, following MHC participation than similar comparison groups or those who proceed through the traditional criminal justice system?

It is hypothesized that criminal offences will be reduced following $\mathrm{MHC}$ involvement for a sample of $\mathrm{MHC}$ participants, and that $\mathrm{MHC}$ participants will have reduced rates of recidivism than similar comparison samples or those who proceeded through the traditional criminal justice 
system. It is also hypothesized that MHC participants will show greater improvements in clinical outcomes than similar comparison samples or those who proceeded through the traditional justice system. 


\section{Method}

Three standard meta-analyses were conducted: One examining the single-group (prepost) criminal offence research on adult and youth MHCs; the second examining the available experimental and quasi-experimental recidivism research on adult and youth MHCs; and the third examining the experimental and quasi-experimental clinical research on adult and youth MHCs. Following the standard meta-analytic reviews, moderator analyses were conducted using the list of moderators outlined below.

An exhaustive literature search was completed using Carleton University's Scholars Portal. Scholar's Portal is run by the Ontario Council of University Libraries (www.scholarsportal.info/) and is a shared database system which provides students of the 21 Universities in Ontario with access to greater than 8,000 scholarly journals (University of Laurier Library, 2012). Google Scholar, mental health association websites, governmental websites (e.g., National Institute of Mental Health), and research websites (e.g., Canadian Mental Health Organization) were also perused for relevant published and unpublished works. Electronic searches were conducted using a variety of key words and Boolean Operators (e.g., AND, OR). Some of the key words included the following: mental health court, youth mental health court, adult mental health court, problem solving court, treatment court, juvenile, young offender, behavioural court, behavioural health court, mental health, diversion, treatment, mental illness, effectiveness, outcomes, Canada.

\section{Study Inclusion Criteria}

The inclusion criteria was as follows: (1) Available in English; (2) Completed (not in progress); (3) Studies conducted in Canada or the United States; (4) Youth or Adult Mental Health Court; (5) MHC studies of youth and adults of all ages were included so long as mental health was a primary focus of the court; (6) Sufficient statistical results to permit 
calculation of at least one effect size; (7) Single group (pre-post), experimental or quasiexperimental study design; (8) At least one quantifiable clinical (e.g., measures of psychosocial functioning or hospitalization), criminal offence, or recidivism outcome. Quasi-experimental studies are those with comparison groups but lack random assignment of participants to the intervention.

An important study inclusion decision needed to be made in regards to Morin's (2004) Dissertation which evaluated a MHC in Hennepin County, Minnesota. Morin's (2004) quasiexperimental study design included a MHC sample with a diagnosed mental illness and a traditional court comparison sample that did not have mental health status assessed. It was deemed appropriate to include the Morin (2004) study in light of the known overrepresentation of persons with mental illness in the traditional criminal justice system, and because the court identified and functioned as a MHC (Linhorst, Dirks-Linhorst, Stiffelman, Gianino, Bernsen, \& Kelley, 2009; Markowitz, 2011; Redlich, Liu, Steadmean, Callahan, \& Robbins, 2012; Redlich et al., 2010; Schneider, 2008; Skeem, Manchạ, Peterson, 2011). Unfortunately prior to data analysis this study had to be dropped in order not to violate independence of observations.

Another important study inclusion decision pertained to the combined MHC and DTC for young offenders operating in Summit County, Ohio. The youth Crossroads combined mental health and DTC was initially conceptualized as a DTC, but when the Honorable Linda Tucci Teodosio began overseeing the court it was remodeled into a co-occuring substance abuse and mental health treatment court (Buldum, 2005). For her Master of Arts thesis Buldum (2005) conducted an evaluation of the dual court which included a sample of 90 young offenders admitted to the program over the course of almost two years (January 2003 to 
September 2004). The sample included recently accepted participants ( $n=7 ; 8 \%$ ) who had yet to receive a mental health assessment, as a consequence of including those recently enrolled, no mental health data was available for these individuals (Buldum, 2005). Despite the lack of confirmed mental illness for these participants it was considered appropriate to include this study because the court was functioning as a $\mathrm{MHC}$ and mental health assessment data was just not available at that time.

While there are MHCs outside of North America they were not included in the current meta-analytic reviews for a number of reasons. One being that the general underpinnings of the MHCs used in this review are more likely to be dissimilar when MHCs outside of North America are taken into consideration. The MHCs currently operating in the U.S. and Canada are known to lack a rigid model, and it was thought that MHCs outside of these countries would be too fundamentally different to permit their inclusion in the following reviews (Steadman et al., 2005).

England and Wales have established two MHC pilots (one in Stratford and another in Brighton), however, to date there have been no quantitative evaluations of the courts though evaluations are currently in the works (Rutherford, 2010). Moreover, in a report on mental health and criminal justice Rutherford (2010) outlines how the MHC pilots in England and Wales are more similar to Lord Bradley's Criminal Justice Mental Health Teams than they are to the American MHC model. Australian MHCs are mainly known as Mental Health Review Tribunals and primarily deal with voluntary and involuntary commitment decisions regarding persons with mental illness (Australian Institute of Criminology, 2009). To the researcher's knowledge, there are no functioning MHCs in New Zealand. However there is support for a Maori MHC due to the overrepresentation of Maori persons in both New Zealand's criminal 
justice and mental health systems (Toki, 2010).

\section{Study Exclusion Criteria}

The study exclusion criteria was as follows: (1) Not available in English; (2) Studies in progress; (3) Studies of MHCs outside of North America; (4) Lack of statistical results to permit calculation of effect size; (5) Qualitative studies which do not contain sufficient information to calculate an effect size; (6) Lack of quantifiable clinical, offence history, recidivism, incarceration and hospitalization outcomes.

\section{Coding}

A coding manual was created for both the adult and youth MHC studies (see Appendix). The author coded for useful study descriptor variables and all necessary information required for the computation of the effect size of interest (standardized mean difference), and moderator variables. The standardized mean difference was selected as the effect size of interest because not all studies measured the outcomes of interest in the same manner. When studies report on a similar outcome but do not use the same scale, one must use a standardized measure of effect size in order to have meaningful results (Borenstein, Hedges, Higgins, \& Rothstein, 2009). Cohen's $d$ and Hedge's $g$ are both measures of the standardized mean difference (Borenstein et al., 2009). Hedge's $g$ was not used as the effect size measure because it is most appropriate for small sample sizes and a number of the studies included in the present meta-analyses had large sample sizes $(N \geq 200$; Borenstein et al., 2009). As suggested by Cohen (1988), $d=.20$ represents a small effect, $d=.50$ represents a moderate effect, and a $d=.80$ represents a large effect.

For each $\mathrm{MHC}$ sample only one effect size was calculated per outcome measure of interest. Thus if a study of a particular MHC was conducted in 2005 and 2012, only the most recent results for each outcome were used to calculate an effect size for that sample. If 
however the most recent results did not permit calculation of an effect size, and the author of the present study could not obtain the necessary information from the study's author(s), the less recent results were used in the computation of an effect size. A second coder was recruited in order to be able to facilitate interrater reliability analyses. The second coder held a Master of Arts degree and was able to spend time coding $22 \%(n=4)$ of the studies. It should be noted that while the second coder was only able to code four studies due to time constraints, effect size coding was conducted for each of the three meta- analyses at once. Thus while coding one study each coder had to look for enough quantitative information in order to be able to contribute an effect size for each of the meta-analytic reviews. The primary coder identified seven effect sizes while the second coder identified five. For the continuous variables $(n=66)$, the intra-class correlation coefficient (ICC) values ranged from -.91 to 1.00 . The intra-class correlation coefficient was disproportionately low for the length of the follow-up period for the second meta-analysis $(\mathrm{ICC}=-.91)$, and with this variable removed the ICC values ranged from 0 to 1.00 , with the median ICC equal to 1.00 . Four variables which measured the number and percentage of participants who failed to complete a MHC program, and the mean and standard deviation for length of time in a MHC, had an ICC of 0 and with these four variables excluded, the ICC ranged from .86 to 1.00 indicating good reliability. The variables with unreasonably low ICC values were excluded from any analyses.

A measure of interrater agreement, Cohen's kappa was calculable for seven dichotomous/ categorical variables. The resulting Cohen's kappa values had a range of .50 to 1.00 , indicating acceptable interrater reliability. For the remaining categorical variables, percentage of agreement was calculated (number of agreements/ total number of observations) 
and ranged from $0 \%$ to $100 \%$. One variable, source of offence data had zero agreement between raters and so it was not used in any analyses. With this variable removed, the range of Cohen's kappa was from $75 \%$ to $100 \%$, indicating acceptable interrater reliability.

A total of 18 studies met the study inclusion criteria and were coded. Three of the eighteen studies included multiple sites (Rossman et al., 2012; Steadman et al., 2011; Trupin \& Richards, 2003; Table 1). One of the multisite studies (Rossman et al., 2012) had to be treated as a single site study because the two comparison groups shared a largely overlapping sample. Within the two multisite studies that were not treated as a single site, there were a total of 6 unique MHCs, bringing the total number of MHC sites to 22 when all 18 studies were counted (Table 1). Two of the 18 studies were of youth MHCs (Behnken et al., 2009; Buldum, 2005), and an additional two were of a Canadian MHC in Saint John, New Brunswick (Canales, 2011; Wei, Campbell, \& Canales, 2011; Table 1).

Of the 18 coded studies, some contributed effect sizes to more than one review whereas others did not. The first meta-analytic review included 11 out of the possible 18 studies, for a total of 15 independent MHC sites. For the second meta-analysis, there were a total of 12 studies for a total of 15 independent MHC sites. Finally, the third review included a total of 5 single site studies therefore there were $5 \mathrm{MHC}$ sites.

An analysis of the study demographics demonstrated that the majority of MHC participants were white males in their mid to late thirties (Table 2). On average, less than $15 \%$ of MHC participants were Hispanic and approximately $21 \%$ were African-American (Table 2). The percentage of MHC participants diagnosed with schizophrenia, bipolar disorder, and depressive disorders ranged from $4 \%$ to $56 \%, 9 \%$ to $48 \%$, and $7 \%$ to $41 \%$, respectively (Table 3). The majority of studies which met the inclusion criteria had a quasi-experimental design ( $n$ 
$=11 ; 61 \%)$, followed by single group $(n=5 ; 28 \%)$, and experimental designs $(n=2 ; 11 \%$;

Table 4). While some MHCs accepted only misdemeanor offences $(n=6 ; 27 \%)$, most accepted both misdemeanors and felonies $(n=13 ; 59 \%$; Table 4$)$. The bulk of the studies indicated that participants were only enrolled in the MHC after a plea had been entered ( $n=9$; $41 \%)$, but some MHCs accepted participants either pre-plea and post $(n=2 ; 9 \%)$, whereas only one (5\%) MHC identified as only accepting offenders pre-plea (Table 4). Together the quasi-experimental and experimental studies reported most often using a treatment as usual comparison group $(n=10 ; 56 \%$; Table 4). As shown in Table 4, the second most common comparison group included participants who opted out of the MHC, or were either expelled, or deemed ineligible $(n=8 ; 44 \%)$. 
Table 1

Characteristics of Studies $(N=18)$ Included in the Meta-Analytic Reviews

Study Characteristic $n(\%)$

Multisite

$3(1 \%)$

Single Site

$15(8 \%)$

Study Date

2000-2003

$3(17 \%)$

2004-2007

$6(33 \%)$

2008-2011

$8(44 \%)$

2012

$1(\%)$

Publication Status

Unpublished

$11(6 \%)$

Published $7(39 \%)$

Study Design

Experimental

2(11\%)

Quasi-Experimental

$11(6 \%)$

Single Group

$5(28 \%)$

MHC Type

Youth

$2(11 \%)$

Adult

$16(8 \%)$

Country

Canada

2(11\%)

United States

$16(8 \%)$

Outcomes

$$
\begin{array}{ll}
\text { Recidivism/ Criminal Offence History } & 15(8 \%) \\
\text { Clinical } & 5(28 \%)
\end{array}
$$

Note. Total number of studies and percentages for study outcomes exceeds 18 and $100 \%$, respectively, due to some studies $(n=3 ; 17 \%)$ having reported on both clinical and recidivism/ criminal history outcomes. 
Table 2

Mental Health Court Participant Characteristics by Study and Mental Health Court Site

\begin{tabular}{|c|c|c|c|c|c|c|}
\hline Study & $\mathrm{Age}^{\mathrm{a}}$ & Males $^{b}$ & Females $^{b}$ & White $^{b}$ & African-American ${ }^{b}$ & Hispanic $^{b}$ \\
\hline Behnken et al. (2009) & $15.39(1.45)$ & $90(67 \%)$ & $43(33 \%)$ & $45(34 \%)$ & $12(9 \%)$ & $44(33 \%)$ \\
\hline Bess (2004) & $32.30(9.70)$ & $26(52 \%)$ & $24(48 \%)$ & $41(84 \%)$ & $3(6 \%)$ & $2(4 \%)$ \\
\hline Buldum (2005) & 15.61(N.A.) & $60(67 \%)$ & $30(33 \%)$ & $74(82 \%)$ & $12(13 \%)$ & $0(0 \%)$ \\
\hline Canales (2011) & $35.47(12.23)$ & $99(72 \%)$ & $39(28 \%)$ & $132(96 \%)$ & $3(2.2 \%)$ & N.A.(N.A.) \\
\hline Christy et al. (2005) & $36.36(10.40)$ & $77(66 \%)$ & $39(34 \%)$ & $79(68 \%)$ & $26(22 \%)$ & N.A.(N.A.) \\
\hline Cosden et al. (2004) & N.A.(N.A.) & $67(49 \%)$ & $70(51 \%)$ & $97(71 \%)$ & $10(7 \%)$ & $24(18 \%)$ \\
\hline Frailing (2010) & N.A.(N.A.) & $69(47 \%)$ & $73(50 \%)$ & $121(83 \%)$ & $21(13 \%)$ & $4(3 \%)$ \\
\hline Herinckx et al. (2005) & $35(11.00)$ & $206(56 \%)$ & $162(44 \%)$ & $328(89 \%)$ & N.A.(N.A.) & N.A.(N.A.) \\
\hline Hiday \& Ray (2010) & N.A.(N.A.) & $71(72 \%)$ & $28(28 \%)$ & $64(65 \%)$ & $34(34 \%)$ & N.A.(N.A.) \\
\hline McNiel et al. (2011) & $37.5(10.83)$ & $37(66 \%)$ & $19(34 \%)$ & $23(43 \%)$ & N.A.(N.A.) & N.A.(N.A.) \\
\hline Neiswender (2005) & 40.02(N.A.) & $80(70 \%)$ & $34(30 \%)$ & $94(83 \%)$ & N.A.(N.A.) & N.A.(N.A.) \\
\hline Roman (2011) & $36.93(11.25)$ & $28(65 \%)$ & $15(35 \%)$ & $23(54 \%)$ & $15(35 \%)$ & $2(5 \%)$ \\
\hline Rossman et al. (2012a) & 37.3(N.A.) & $404(62 \%)$ & $244(38 \%)$ & $47(7 \%)$ & $219(34 \%)$ & $376(58 \%)$ \\
\hline Rossman et al. (2012b) & 33(N.A.) & $249(76 \%)$ & $78(24 \%)$ & $124(38 \%)$ & $190(58 \%)$ & $69(21 \%)$ \\
\hline Trupin et al. (2000) & $35.6(10.62)$ & $36(78 \%)$ & $10(22 \%)$ & N.A.(N.A.) & N.A.(N.A.) & N.A.(N.A.) \\
\hline
\end{tabular}




\begin{tabular}{|c|c|c|c|c|c|c|}
\hline Trupin et al. (2001) & $37.01(10.58)$ & $48(74 \%)$ & $17(26 \%)$ & $37(57 \%)$ & $22(34 \%)$ & $0(0 \%)$ \\
\hline Trupin et al. (2003a) & $38.57(11.05)$ & N.A. $(75 \%)$ & N.A.(25\%) & N.A. $(60 \%)$ & N.A. $(34 \%)$ & N.A.(N.A.) \\
\hline Trupin et al. (2003b) & $37: 6(10.95)$ & N.A. $(75 \%)$ & N.A. $(75 \%)$ & N.A. $(60 \%)$ & N.A. $(15 \%)$ & N.A.(N.A.) \\
\hline Steadman et al. (2011a) & 37.5(N.A.) & $78(72 \%)$ & $30(28 \%)$ & $42(39 \%)$ & N.A.(N.A.) & $8(7 \%)$ \\
\hline Steadman et al. (2011b) & 38.1(N.A.) & $75(55 \%)$ & $61(45 \%)$ & $103(76 \%)$ & N.A.(N.A.) & $37(27 \%)$ \\
\hline Steadman et al. (2011c) & 38.1(N.A.) & $56(54 \%)$ & $48(46 \%)$ & $54(52 \%)$ & N.A.(N.A.) & $2(2 \%)$ \\
\hline Steadman et al. (2011d) & 36:3(N.A.) & $51(52 \%)$ & $48(49 \%)$ & $54(55 \%)$ & N.A.(N.A.) & $0(0 \%)$ \\
\hline Wei et al. $(2011)^{*}$ & 35(N.A.) & $>77(>65 \%)$ & $>24(>20 \%)$ & $>107(>90 \%)$ & $<6(<5 \%)$ & N.A.(N.A.) \\
\hline
\end{tabular}

Note. Rossman et al. (2012) study is included twice (once for each of the different mental health court sites) but the multisite aspect of the study was collapsed in data analysis due to an overlapping comparison sample between the Brooklyn and Bronx mental health courts.

* = study characteristics for the Wei et al. (2011) study were obtained from a related conference presentation by Moser, Campbell, Canales, \& Wei (2011).

${ }^{a}$ For the age column means are provided with standard deviations in parentheses.

b. Columns are sample sizes followed by percentages in parentheses. 
Table 3

Mental Health Court Participant Mental Health Diagnoses by Study and Mental Health Court Site

\begin{tabular}{|c|c|c|c|}
\hline Study & Schizophrenia $^{a}$ & Bipolar Disorder $^{a}$ & Depressive Disorders $^{a}$ \\
\hline Behnken et al. (2009) & $5(4 \%)$ & $51(38 \%)$ & $68(41 \%)$ \\
\hline Bess (2004) & N.A.(N.A.) & $12(25 \%)$ & $10(20 \%)$ \\
\hline Buldum (2005) & N.A.(N.A.) & $4(40 \%)$ & N.A.(N.A.) \\
\hline Canales (2011) & N.A.(N.A.) & $22(16 \%)$ & $15(11 \%)$ \\
\hline Christy et al. (2005) & N.A.(N.A.) & N.A.(N.A.) & N.A.(N.A.) \\
\hline Cosden et al. (2004) & N.A.(N.A.) & $32(23 \%)$ & N.A.(N.A.) \\
\hline Frailing (2010) & N.A.(N.A.) & $32(23 \%)$ & N.A.(N.A.) \\
\hline Herinckx et al. (2005) & $82(22 \%)$ & N.A.(N.A.) & N.A.(N.A.) \\
\hline Hiday \& Ray (2010) & N.A.(N.A.) & N.A.(N.A.) & N.A.(N.A.) \\
\hline McNiel et al. (2011) & $25(45 \%)$ & $6(11 \%)$ & $8(14 \%)$ \\
\hline Neiswender (2005) & N.A.(N.A.) & N.A.(N.A.\%) & N.A.(N.A.) \\
\hline Roman (2011) & $6(14 \%)$ & $18(42 \%)$ & $3(7 \%)$ \\
\hline Rossman et al. (2012a) & N.A.(N.A.) & N.A.(N.A.) & N.A.(N.A.) \\
\hline Rossman et al. (2012b) & N.A.(N.A.) & N.A.(N.A.) & N.A.(N.A.) \\
\hline Trupin et al. (2000) & N.A.(N.A.) & N.A.(N.A.) & N.A.(N.A.). \\
\hline
\end{tabular}


Trupin et al. (2001)

Trupin et al. (2003a)

Trupin et al. (2003b)

Steadman et al. (2011a)

Steadman et al. (2011b)

Steadman et al. (2011c)

Steadman et al. (2011d)

Wei et al. (2011)

$\begin{array}{lll}\text { N.A.(N.A.) } & \text { N.A.(N.A.) } & \text { N.A.(N.A.) } \\ \text { N.A.(N.A.) } & \text { N.A.(N.A.) } & \text { N.A.(N.A.) } \\ \text { N.A.(N.A.) } & \text { N.A.(N.A.) } & \text { N.A.(N.A.) } \\ 61(56 \%) & 10(9 \%) & 17(16 \%) \\ 44(32 \%) & 33(24 \%) & 32(24 \%) \\ 37(36 \%) & 36(35 \%) & 25(24 \%) \\ 38(38 \%) & 47(48 \%) & 11(11 \%) \\ \text { N.A.(N.A.) } & \text { N.A.(N.A.) } & \text { N.A.(N.A.) }\end{array}$

Note. Rossman et al. (2012) study is included twice (once for each of the different mental health court sites) but the multisite aspect of the study was collapsed in data analysis due to an overlapping comparison sample between the Brooklyn and Bronx mental health courts.

${ }^{a}$ Columns are sample sizes followed by percentages in parentheses. 
Table 4

Study Characteristics by Mental Health Court Site $(N=22)$ and Study $(N=18)$

\begin{tabular}{|c|c|c|c|c|}
\hline MHC Study & Study Design & Index Offences & Plea Type & Comparison Group \\
\hline Behnken et al. (2009) & Single Group & Felony \& Misdemeanour & Unknown & Not Applicable \\
\hline Bess (2004) & Experimental & Felony \& Misdemeanour & Unknown & Treatment as Usual \\
\hline Buldum (2005) & Quasi-Experimental & Unknown & Unknown & Other Treatment $^{d}$ \\
\hline Canales (2011) & Single Group & Unknown & Unknown & $\begin{array}{l}\text { Expelled/Opt Out/ } \\
\text { Ineligible }^{\mathrm{e}}\end{array}$ \\
\hline Christy et al. (2005) & Quasi-Experimental & Misdemeanour & Pre-Plea & Treatment as Usual \\
\hline Cosden et al. (2004) & Experimental & Felony \& Misdemeanour & Pre \& Post-Plea & Treatment as Usual \\
\hline Frailing (2010) & Quasi-Experimental & Felony \& Misdemeanour & Post-Plea & Ineligible/ Opt Out ${ }^{\mathrm{f}}$ \\
\hline Herinckx et al. (2005) & Single Group & Misdemeanour & Post-Plea & Not Applicable \\
\hline Hiday \& Ray (2010) & Quasi-Experimental & Felony \& Misdemeanour & Pre \& Post-Plea & Opt Out/ Expelled \\
\hline McNiel et al. (2011) & Quasi-Experimental & Felony \& Misdemeanour & Unknown & Treatment as Usual \\
\hline Neiswender (2005) & Quasi-Experimental & Misdemeanour & Post-Plea & Opt Out \\
\hline Roman (2011) & Quasi-Experimental & Felony \& Misdemeanour & Post-Plea & Ineligible/ Opt Out ${ }^{\mathrm{g}}$ \\
\hline Rossman et al. $(2012 a)^{a}$ & Quasi-Experimental & Felony \& Misdemeanour & Post-Plea & Treatment as Usual \\
\hline Rossman et al. $(2012 b)^{a}$ & Quasi-Experimental & Felony \& Misdemeanour & Post-Plea & Treatment as Usual \\
\hline
\end{tabular}


Trupin et al. (2000)

Trupin et al. (2001)

Trupin et al. (2003a)

Trupin et al. (2003b)

Steadman et al. (2011a)

Steadman et al. (2011b)

Steadman et al. (2011c)

Steadman et al. (2011d)

Wei et al. (2011)
Quasi-Experimental

\section{Single Group}

Quasi-Experimental

Quasi-Experimental

Quasi-Experimental

Quasi-Experimental

Quasi-Experimental

Quasi-Experimental

Single Group
Misdemeanour

Unknown

Misdemeanour

Misdemeanour

Felony \& Misdemeanour

Felony \& Misdemeanour

Felony \& Misdemeanour

Felony \& Misdemeanour

Unknown
Unknown

Post-Plea

Post-Plea

Post-Plea

Unknown $^{\mathrm{c}}$

Unknown $^{c}$

Unknown ${ }^{\mathrm{c}}$

Unknown $^{\mathrm{c}}$

Unknown
Opt Out

Opt Out ${ }^{\mathrm{h}}$

Opt Out

Opt Out

Treatment as Usual

Treatment as Usual

Treatment as Usual

Treatment as Usual

Not Applicable

Note. Index offences refer to the type of offences for which an offender can be admitted into the mental health court, and plea type refers to whether the court accepts participants pre or post-plea. Treatment as usual is considered traditional criminal justice system processing.

${ }^{a}=$ Rossman et al. (2012) study is included twice (once for each of the different mental health court sites) but the multisite aspect of the study was collapsed in data analysis due to an overlapping comparison sample between the Brooklyn and Bronx mental health courts.

${ }^{b}=$ Study characteristics for the Wei et al. (2011) study were obtained from a related conference presentation by Moser, Campbell, Canales, \& Wei (2011).

${ }^{c}=$ While it is unclear whether this court requires a plea prior to MHC enrollment, participants are referred to this court post-booking.

$\mathrm{d}=$ The comparison group received a less intensive form of mental health court treatment.

$\mathrm{e}=$ The Canales (2011) study was primarily a pre-post study, but with information obtained from the author coupled with data presented in the study, the present author was able to use this study in the comparison group analyses. Ineligible for the Canales (2011) study meant that the participants were not admitted to the court, and the reasons for which are unknown.

$\mathrm{f}=$ For this study participants may have been ineligible because they had an alternative disposition of their case.

$\mathbf{g}=$ For this study ineligible meant that the participants met the entry criteria but were deemed ineligible because the court was at its quota.

${ }^{\mathrm{h}}=$ The Trupin et al. (2001) study was primarily a single group study, however, there was a comparison between those MHC participants who opted in and out of the program in the Appendix of this study. 


\section{Statistical Analysis}

Data was entered into and analyzed using Comprehensive Meta-analysis (version 2.0; CMA). Meta-analytic results were screened for outliers, appropriate weights assigned to studies, violations of independence of observations, and variability across studies. Sensitivity analyses were conducted and reported when results with and without alterations (e.g., imputed correlation coefficients) needed to be compared. Moderator analyses were conducted for the two meta- analytic reviews of criminal offence outcomes because they had an appropriate number of studies for conducting moderator analyses (15-20; Helmus \& Babchishin, 201a). Lastly, publication bias was assessed for all three of the meta-analytic reviews.

If a study reported the necessary numerical information to calculate an effect size but failed to indicate whether the test was a one-tailed or two-tailed test the author set CMA to calculate the effect size based on a one-tailed test. The reason a one-tailed test was used is because most studies hypothesized $a$ priori that they expected to see a reduction in the commission of criminal offences or better psychosocial functioning. In addition, a one-tailed test makes the statistical test more conservative as it is harder to detect a significant effect and the computed standardized mean difference will be smaller. For example, the Behnken et al. (2009) study reported the necessary numerical information to calculate an effect size but did not indicate if the $t$-test was one-tailed. Using a one-tailed test the computed standardized mean difference is -.40 whereas with a two- tailed test the standardized mean difference is 43. For studies that reported the necessary numerical information to calculate an effect size but instead of reporting the exact $p$-value it was reported as $p<.001$ for example, the author used a $p$-value of .001 in the computation of the standardized mean difference. This was considered acceptable because it is standard practice to report a $p$-value $<.001$ if the $p$-value is quite small. 
At the time of statistical analyses the author of the current study was still awaiting the site specific standard deviations from Dr. Roumen Vesselinov of the multisite study conducted by Steadman and colleagues (2011). The multisite study examined recidivism, as measured by annualized rearrest rates, for four MHC sites across the.U.S.: Indianapolis; Santa Clara, California; Minneapolis; and, San Francisco, California (Steadman et al., 2011). The present author did not want to exclude such valuable information for multiple MHC sites, but was missing the site specific standard deviations for each point of measurement (18 months prior to and following MHC enrollment). In order to avoid treating the multisite study as one site, by using the reported total mean and standard deviation collapsed across the four MHCs, the current author had to use the pooled standard deviation in replace of each of the site specific standard deviations. This method required the present author to assume that the pooled standard deviation was applicable for each MHC site. Using the pooled standard deviation was considered an acceptable method for calculating an effect size, albeit with some bias (Helmus \& Babchishin, 2012).

\section{Heterogeneity across studies}

The heterogeneity of effect sizes were explored using Cochran's $Q$ statistic and $I^{2}$. Regardless of the heterogeneity findings both fixed and random effects results were reported. One reason that both results were reported was that there has been mixed findings about the ability of homogeneity tests to accurately identify heterogeneous population effects because of a known lack of statistical power when there are too few studies (Field, 2005). Both sets of results (fixed and random) will also be reported so that other researchers may have a better understanding of the current study and so the difference between the results may be compared. 
Both random and fixed effects use the inverse of the variance of each study's effect size as the study weight (Helmus, Hanson, Babchishin, \& Mann, in press).

Cochran's $Q$ statistic is a standardized measure of the variability between effect sizes (Borenstein et al., 2009). A statistically significant $Q$ statistic indicates that there is more variability between studies (effect sizes) than would be due to chance. A statistically significant $Q$ statistic also indicates that the assumptions of the fixed effects method are untenable because the studies are not estimates of the same effect size, but rather are sampling from a distribution of possible effect sizes (Field \& Gillett, 2010; Hedges, 1992). In addition to the results being untenable, the confidence interval (CI) for the fixed effects method becomes overly narrow whereas the random effects method takes on a more conservative CI (Field \& Gillett, 2010). $I^{2}((Q-d f) / Q)$ is a standardized measure of variability that ranges from 0 to 100 and while negative scores are technically possible, they should be treated as a 0 (Borenstein et al., 2009). $I^{2}$ scores may be interpreted as the percentage of the total variability ( $Q$ statistic) that is greater than what would be expected by random sampling error or chance (Borenstein et al., 2009). If there was significant variability across studies the meta-analytic results were examined for potential outliers.

According to the author's guideline, if there were outliers they would account for a large proportion of the variability of the $Q$ statistic (greater than $50 \%$ ) and as such, upon removal variability would be greatly reduced (Hanson \& Bussière, 1998). In order for an effect size to qualify as an outlier the $Q$ statistic must be significant, the effect size in question must be the most extreme positive or negative effect size, and account more than $50 \%$ of the variance in the $Q$ statistic (Hanson \& Bussière, 1998). If there was evidence of an outlier results were presented both with and without the outlier. It should also be noted that in the 
event the variability between studies was less than would be expected by chance $(Q<d f)$, the results from the fixed and random effects methods would be the same (Field \& Gillett, 2010). The reason that the results would be the same is because the random-effects model includes an additional error component that becomes zero when the variability is just due to sampling error (Cochrane Collaboration, 2012; Field \& Gillett, 2010).

If there was still evidence of heterogeneity after outliers had been removed, a randomeffects meta-analytic method was most appropriate (Field \& Gillett, 2010). Conceptually a random effects method allows the researcher to generalize their findings beyond the studies included in the analysis whereas a fixed effect method restricts the author's interpretation to only the studies included in the meta-analysis (Borenstein et al., 2009; Field \& Gillett, 2010). For interpretational reasons the author preferred a random effects method. If there was evidence of true variability between studies it was believed to have been the result of the heterogeneity of the samples and varying degrees of treatment and access to care MHC participants receive at various sites. Each MHC is unique in which types of participants it accepts and the types of services which are made available to participants. For example, some courts allow those charged with only misdemeanors or misdemeanors and felonies to enter a MHC.

There is enough similarity between studies however to warrant meta-analytic reviews. The study similarities are as follows: (1) A single court docket for mentally ill offenders; (2) An inter-disciplinary MHC team made up of professionals from both the criminal justice and mental health fields who will design, implement and oversee participant treatment plans; (3) Guarantee that MHC participants will receive the treatment and aid as outlined by their treatment plan; (4) Judicial supervision with enforcement of treatment 
plans through the use of sanctions for negative behaviour (Steadman et al., 2001; Tyuse \& Linhorst, 2005). These four similarities are the same criteria Steadman et al. (2001) use to identify a MHC.

\section{Moderator Analysis}

After the standard meta-analyses for the pre-post criminal offence history and postgroup recidivism reviews had been completed more advanced moderator analyses were conducted. Moderator analyses were only conducted for these reviews because of a sufficient number of studies for moderator analyses (Helmus \& Babchishin, 2012). It was hypothesized that the moderators would account for any heterogeneity between studies that was not due to chance alone (Field \& Gillett, 2010). The fixed effects moderator analyses were reported in order for the researcher to be able to interpret the within-level $Q$ statistics and because it maximizes statistical power (Borenstein et al., 2009). The $p$-value for the moderator analyses were calculated using Dr. Daniel Soper's (2012) chi-square online calculator. The hypothesized moderators were as follows: published versus unpublished, country (U.S. versus Canada); dual-diagnosis exclusive MHC versus dual-diagnosis non-exclusive $\mathrm{MHC}$; $\mathrm{MHC}$ accepted index offences (misdemeanor, felony, both misdemeanor and felony); youth versus adult MHC; and, methodological quality (random assignment, quasi-experimental, drop outs/ expelled/ ineligible). As noted above, quasi-experimental studies are those with comparison groups but lack random assignment of participants to the intervention.

Some MHCs require the diagnosis of a concurrent mental illness and substance abuse disorder; these courts are sometimes referred to as dual-diagnosis MHCs. In a study of 90 MHCs across the U.S., Redlich et al. (2006) found that approximately $25 \%$ of the MHCs studied required participants to have both mental health and substance abuse problems. It should be mentioned that some but not all dual-diagnosis MHCs limit the eligibility of 
offenders without a co- occurring substance abuse disorder (Redlich et al., 2005). For example, the Santa Clara County MHC in California is a dual-diagnosis court but accepts almost all referrals and does not reject potential participants if they do not have both a mental health and substance abuse disorder (Redlich et al., 2006).

The reason for which some MHCs do not identify as dual-diagnosis courts may be that they are unable to deliver substance abuse treatment. Steadman et al. (2005) indicated that certain non dual-diagnosis MHCs do not permit offenders with a diagnosed co-occuring substance disorder to partake in a non dual-diagnosis MHC because of a lack of resources available to draw upon in that particular community. As such some non dual-diagnosis MHCs may not advertise or form the basis of their participant's court involvement around substance abuse disorders because of a lack of community resources. This does not mean that substance abuse disorders are not dealt with in non dual-diagnosis MHCs; they are just not one of the primary reasons for which an offender is participating in that MHC. This is because if the diagnosed substance disorder were one of the primary reasons for which an offender was participating in a $\mathrm{MHC}$, the court would have to ensure that they are able to deliver client centered mental health and substance abuse treatment. If this is not feasible it stands to reason that the MHC model would be a non dual-diagnosis one.

Dual-diagnosis courts may report using time in jail as a sanction more often than non dual-diagnosis courts and for this reason number of days spent in jail throughout the course of a participant's MHC involvement may be skewed in samples from dual-diagnosis courts (Redlich et al., 2006). A possible skew of number of days in jail may have an impact on rates of recidivism. Dual-diagnosis MHCs may resemble DTCs more than non dual-diagnosis MHCs with their increased use of jail as a sanction. The use of sanctions (e.g., jail time) is a 
key feature of DTCs but not MHCs (Griffin, Steadman, \& Petrila, 2002). While DTCs are not part of the scope of this study dual-diagnosis courts are technically a form of MHC and satisfy Steadman et al. (2001) MHC criteria (see below). In addition, in the above aforementioned MHC study conducted by Redlich et al. (2006), they found that identification as a dualdiagnosis exclusive MHC did not significantly predict use of jail as a sanction for noncompliance. The use of jail as a sanction is highly dependent upon the judge overseeing each MHC therefore it is possible that a dual-diagnosis MHC judge may not in fact impose jail as a sanction more often than other MHC judges. It should be noted that a common criticism of dual-diagnosis courts is that the increased use of jail time as a sanction is counterintuitive and runs contrary to the aim of MHCs (Griffin et al., 2002; Redlich et al., 2006). Based on these findings dual-diagnosis exclusive and non- exclusive MHCs will be included in the present study.

After coding, it became clear that none of the studies required a diagnosis of both substance abuse and a mental illness, and either the studies failed to mention that they required a dual-diagnosis or they accepted participants with a mental illness regardless of whether or not they had a substance abuse disorder. As previously mentioned, the youth Crossroads court studied in Buldum's (2005) thesis identified as a co-occurring drug and MHC, but not all of the court's participants (32.2\%) were identified as having a substance abuse disorder. Almost three quarters of the sample (71.1\%) were not abusing at time of entry (Buldum, 2005). Without having enough studies that identified as a dual-diagnosis exclusive court, this moderator had to be dropped from the analyses. The majority of studies did indicate that participants had a dual diagnosis but it was not a requirement in order to be accepted into the MHC. 
Type of court (adult versus youth) and country had to be dropped as moderators because these variables had greater than a 90-10 split between categories and had they been included, the smaller category would have exerted undue influence on the analysis (as cited in Tabachnick \& Fidell, 2007). Type of index offences accepted into the court was used as a moderator because MHCs which accept more severe index offences may be more likely to use jail time as a sanction, which could impact recidivism rates. Publication status was used as a moderator in order to further investigate the possibility of publication bias. Study design (random assignment, treatment as usual, drop out/ expelled) was used as a measure of the methodological quality of the studies.

As a means to assess the methodological quality of the included studies, the author considered examining the effects of studies where the comparison group received an alternative form of treatment versus no treatment at all. When considering this analysis it came to light that for all of the experimental and quasi-experimental studies, the comparison groups were predominately composed of offenders who opted out of the MHC program, were expelled or ineligible, or made up of those who proceeded with traditional criminal justice system processing (treatment as usual; Table 4). There was only one study (Buldum, 2005) which compared the MHC group with an alternative treatment, a less intensive version of the MHC program, and so the author decided not to explore this relationship. Instead the author choose to explore a moderator which took into consideration the design of a study (e.g., experimental), and the nature of the comparison group (e.g., quasi-experimental with offender matching on demographic variables). After having reviewed the studies it became evident that the author could assess the internal validity of studies by comparing those which followed a true experimental a design versus those studies with more variable validity: quasi-experimental 
design with a matched treatment as usual comparison group; quasi-experimental design without a matched treatment as usual comparison group; and, studies with comparison groups consisting of participants who were expelled, ineligible, or dropped out of the MHC program.

There was one quasi-experimental study with a treatment as usual comparison group which did not match participants on any variables and as a result, the author decided to drop this category of the moderator (Buldum, 2005). The remaining quasi-experimental studies with treatment as usual comparison groups matched participants on a variety of variables, however none matched participants on risk of recidivism (Christy et al., 2005; McNiel et al., 2011; Rossman et al., 2012; Steadman et al., 2011). Participants were mainly matched on demographics, mental health diagnoses, and previous criminal history. Christy and colleagues (2005) also matched participants on current psychiatric symptom severity. Two studies had experimental designs with treatment as usual comparison groups (Table 4). The final seven studies had comparison groups which included participants who opted out, were expelled, or were deemed ineligible for the MHC program (Table 4).

\section{Publication Bias}

It has been well established that papers that report significant findings are more likely to be published in journals than those papers that do not find significance (Dickersin, Min, \& Meinert, 1992). As a means of reducing publication bias, a search of the grey literature was conducted on top of using traditional article retrieval methods (e.g., PsycINFO via Scholar's Portal) to accumulate articles. In addition, reference lists of previously obtained journal articles were reviewed in hopes of finding relevant articles. The researcher made every attempt to contact authors of studies that did not report sufficient information to permit calculation of effect sizes. In fact the author contacted at least one author of every study that did not include sufficient information to calculate an effect size. The two studies (Canales, 
2011; Wei et al., 2011) of the Saint John MHC in New Brunswick were included in the present study because of a successful search of a conference abstract book. Most of the studies included in this meta-analysis $(61 \% ; n=11)$ were not found in journals but were considered grey literature.

After having conducted the meta-analyses, to investigate the possibility of publication bias Rosenthal's (1979) fail-safe $N$, and Orwin's (1983) fail-safe $N$, and Begg and Mazumdar's (1994) rank correlation test were reported. Funnel plots were created by CMA and were used in order to visually investigate for publication bias. A variety of different publication bias techniques were utilized because of their different benefits and to decrease the likelihood of failing to identify publication bias (Sarteschi et al., 2011). Rosenthal's (1979) failsafe $N$ is the number of missing studies with an effect size of zero which would be required to turn one's significant mean weighted effect size into a nonsignificant effect (Borenstein et al., 2009). Orwin's (1983) failsafe $N$ is a variation of Rosenthal's failsafe $N$ that does not rely on statistical significance, and does not require the missing studies to have an effect size of zero (Borenstein et al., 2009). Orwin's failsafe $N$ allows the researcher to control the average effect size of the missing studies, and specify the smallest (most trivial) effect size that would be of interest to the researcher (Borenstein et al., 2009). Using Kendall's tau ( $\tau$ ) correlation coefficient, Begg and Mazumdar's (1979) rank correlation test is a formal test for publication bias that produces a correlation between the standardized effect size and its variance (Field \& Gillett, 2012;). Publication bias is evidenced by a strong and significant correlation coefficient (Field \& Gillett, 2010). Begg and Mazumdar's (1994) rank correlation test has been criticized for lacking statistical power in small meta-analyses unless there is substantial publication bias (Begg \& Mazumdar, 1994; Field \& Gillett, 2010). 


\section{Results}

\section{Criminal Offence History and Mental Health Courts}

The first meta-analytic review examined the efficacy of adult and youth mental health courts in terms of criminal offences. Mean number of offences prior to mental health court involvement was compared to mean number of offences following MHC involvement.

Depending on the study, number of offences prior to and following MHC involvement could have been measured according to time of referral, entry into the MHC, or another point of interest. The measure of criminal offence history was dependent on the study, with some studies using number of arrests (Behnken et al., 2009; Herinckx et al., 2005) or annualized arrest rates (Steadman et al., 2011) prior to and following MHC involvement, whereas other researchers used number of bookings (Bess, 2004), and number of convictions (Bess, 2004). It was often unclear whether or not the index offence which brought the offender to the MHC was included in analyses. In their study Steadman and colleagues (2011) indicated that MHC participants had at least one offence as each of the four sites included in their evaluation were post-booking MHCs.

A total of 11 studies contributed an effect size to this meta-analysis, for a total of 15 MHC sites. Three studies (Bess, 2004; Cosden et al., 2004; Trupin et al., 2003) had multiple effect sizes that were collapsed to create one aggregate mean effect size for the study or for each site if the study was a multisite study. Effect sizes were also collapsed across subgroups and so the study was used as the unit of analysis. One study (Cosden et al., 2005) included pre-post criminal history information for multiple groups. Effect sizes were coded so that a negative effect size represented a reduction in criminal offences following $\mathrm{MHC}$ involvement. Fifteen studies were included in this meta-analytic review and effect sizes ranged from -1.30 to .13 (Table 5). The total sample size for the present meta-analysis was $N=1,996$, and this includes all non- 
independent observations for each measure of criminal offences and each subgroup. One of the studies (Behnken et al., 2009) was of a youth MHC and one study (Canales, 2011) was of an adult MHC in Canada, the other thirteen were of adult MHCs in the U.S. 


\section{Table 5}

Sample Sizes and Effect Sizes for the First Meta-Analytic Review by Study $(N=11)$ and $M H C$ Site $(N=15)$

\begin{tabular}{|c|c|c|c|c|}
\hline & & & \multicolumn{2}{|c|}{$95 \% \mathrm{CI}$} \\
\hline MHC Study & $N$ & Cohen's $d$ & $L L$ & $U L$ \\
\hline Behnken et al. (2009) & 64 & -.49 & -.75 & -.23 \\
\hline Bess (2004) & 18 & -.65 & -1.28 & -.03 \\
\hline Canales (2011) & 138 & -.55 & -.75 & -.35 \\
\hline Christy et al. (2005) & 116 & -.43 & -.66 & -.23 \\
\hline Cosden et al. (2004) & $13-108^{*}$ & .13 & -.10 & .35 \\
\hline Frailing (2010) & 86 & -.79 & -1.03 & -.55 \\
\hline Herinckx et al. (2005) & 368 & -.31 & -.41 & -.20 \\
\hline Hiday \& Ray (2010) & 60 & -.70 & -.98 & -.42 \\
\hline Roman (2011) & 43 & -1.30 & -1.78 & -.82 \\
\hline Steadman et al. (2011a) & 108 & -.23 & -.47 & -.00 \\
\hline Steadman et al. (2011b) & 136 & -.40 & -.63 & -.17 \\
\hline Steadman et al. (2011c) & 99 & -.23 & -.44 & -.03 \\
\hline Steadman et al. (2011d) & 211 & -.27 & -.51 & -.03 \\
\hline Trupin et al. (2003a) & 65 & -.34 & -.86 & .18 \\
\hline Trupin et al. (2003b) & 31 & -.17 & -.78 & .43 \\
\hline
\end{tabular}

Note. $\mathrm{CI}=$ confidence interval; $L L=$ lower limit; $U L=$ upper limit.

$*=$ different measures of one outcome were associated with different sample sizes and so the range of sample sizes are provided. 
Two studies (Behnken et al., 2009; Steadman et al., 2011) included in this metaanalytic review studied two different MHCs in the same county: Santa Clara County, California. The Behnken and colleagues (2009) study examined criminal history outcomes for a youth MHC while the Steadman and colleagues (2011) study examined criminal offence outcomes for an adult MHC. The two samples data collection periods substantially overlapped, 2005 to 2008 for Steadman and colleagues (2011) and 2007 to 2008 for the Behnken and colleagues (2009) study. With the substantial overlap and same end year it was considered acceptable to include these two studies because a participant of the youth MHC could not have been included in the adult MHCs sample at the same time.

Four studies (Bess, 2004; Cosden et al., 2004; Román, 2011; Steadman et al., 2011) included pre-post means and standard deviations but did not include the correlation between pre- post scores. Without having a correlation one cannot compute a standardized mean difference between pre-post scores and consequently, a study without this information cannot be meta- analyzed (Borenstein et al., 2009). This is not an uncommon predicament for a synthesist to find oneself in (Polanin, 2012). In order to include these studies in the current meta-analysis a pre- post correlation needed to be imputed (Polanin, 2012). The average correlation between pre-post scores was calculated from the studies that reported pre-post correlations and this average (.295) was used as the correlation for the other studies (Polanin, 2012). A sensitivity analysis was then performed to compare the meta-analysis results using the average correlation against the results of the meta-analysis when a correlation of zero was used in replace of the average correlation (Polanin, 2012). If there isn't a large difference between the mean weighted effect size between the two results then it is considered acceptable to use the imputed average correlation (Polanin, 2012). 
The fixed mean weighted effect size with the imputed correlation was $-.37(95 \% \mathrm{CI}$ of -.43 to -.31$)$. The random mean weight effect size with the imputed correlation was $-.42(95 \%$ CI of -.56 to -.29 ). The fixed mean weighted effect size with a correlation of zero was -.38 (95\% CI of -.45 to -.32$)$. The random mean weighted effect size with a correlation of zero was $-.42(95 \%$ CI of -.56 to -.29$)$. The fixed mean weighted effect sizes with the imputed correlation versus the correlation of zero were almost identical, a difference of -.01 . The random mean weighted effect sizes were identical. With the results being very similar for the fixed and random effects, it was considered acceptable to use the imputed correlations.

A second sensitivity analysis was conducted because one study (Bess, 2004) had preMHC criminal history statistics for 50 participants but due to unspecified reasons the author only had follow-up offence information for 18 participants. In this case the sensitivity analysis was conducted by comparing the meta-analytic results using a sample size of 18 versus 50 . If the results are similar the author will use the smaller sample size given that the smaller sample size contributed criminal offence information at both measured time points. The mean weighted effect size for the fixed effects model with the Bess (2004) study having a sample size of 18 was $-.37(95 \% \mathrm{CI}$ of -.43 to -.31$)$. The mean weighted effect size for the random effects model with a sample size of 18 was $-.42(95 \%$ CI of -.56 to -.29$)$. The fixed mean weighted effect size with a sample size of 50 was $-.37(95 \%$ CI of -.43 to -.32$)$. The random mean weighted effect size with a sample size of 50 was -.43 (95\% CI of -.56 to .29). With identical mean weighted effect sizes for the fixed effect results and only a difference of .01 between the random effect results, the author proceeded with using the results that pertain to the smaller sample size. 
Cochran's $Q$ statistic was significant thereby indicating that there is significant heterogeneity across studies and more than would be expected by chance $(Q=60.94, d f=14, p$ $<.001, I^{2}=77.03 ;$ Table 6$)$. Like the $Q$ statistic the $I^{2}$ indicates that there is much variability across studies and most (77\%) is more than what you would expect by chance (Higgins, Thompson, Deeks, \& Altman, 2003). With significant variability across studies the metaanalytic results were examined for potential outliers. In this case the most extreme values were not associated with the largest weights therefore there were no outliers, and so there is evidence of true variability between the studies (Borenstein et al., 2009). 
Table 6

Results of the Meta-Analytic Reviews

\begin{tabular}{|c|c|c|c|c|c|c|c|}
\hline \multirow[b]{2}{*}{ Moderator } & \multicolumn{2}{|c|}{ Fixed Effects } & \multicolumn{2}{|c|}{ Random Effects } & \multirow[b]{2}{*}{$Q$} & \multirow[b]{2}{*}{$I^{2}$} & \multirow[b]{2}{*}{$k\left(n^{\mathrm{a}}\right)$} \\
\hline & $d$ & $95 \% \mathrm{CI}$ & $d$ & $95 \% \mathrm{CI}$ & & & \\
\hline \multicolumn{8}{|l|}{ Single Group } \\
\hline Criminal Offences & -.37 & $-.43,-.31$ & -.42 & $-.56,-.29$ & $60.94 * *$ & 77.03 & $15(1,996)$ \\
\hline Between-Group & & & & & & & \\
\hline Recidivism & -.19 & $-.25,-.13$ & -.25 & $-.42,-.08$ & $83.76^{* *}$ & 83.29 & $15(6,786)$ \\
\hline Clinical Meta-Analysis & -.02 & $-.18, .15$ & -.01 & $-.34, .32$ & $15.85^{*}$ & 74.76 & $5(3,396)$ \\
\hline
\end{tabular}

Note. $\mathrm{CI}=$ confidence interval. $k=$ number of studies.

${ }^{\mathrm{a}}=$ total number of observations used to calculate the effect, they are not independent.

${ }^{*} \mathrm{p}<.01,{ }^{* *} p<.001$ 
There were no extreme weights assigned to any one study. The study with the largest assigned weight was the Herinckx et al. (2005) study. The Herinckx et al. (2005) study had a weight of 31.25 in the fixed effects analysis and a weight of 9.27 in the random effects analysis. Study weights are partially determined by sample size and in this case, the Herinckx et al. (2005) study had the largest sample size $(N=368$; Borenstein et al., 2009). An extremely large weight is a more concerning problem for fixed effects analysis because of how the weight is calculated (based only on within-study variance; Borenstein et al., 2009). While there are no hard and steadfast rules about what constitutes an unusually large weight, in comparison to other researcher's works the above aforementioned weights are not disconcerting (Helmus \& Babchishin, 2012). The study weight being less concerning in the random effects analysis lends further support to the author's attention being primarily directed to the interpretation of the random effects analysis.

Using the fixed effects method there was a statistically significant reduction in criminal offences for MHC participants $(d=-.37,95 \%$ CI $[-.43,-.31]$; Table 6). This was considered a small effect. Using the random effects analysis there was a statistically significant reduction in criminal offences for MHC participants $(d=-.42,95 \% \mathrm{CI}[-.56,-.29]$; Table 6; Figure 1). This was considered a small to medium effect. The funnel plot produced by CMA showed no publication bias as there was evidence of symmetry around the mean weighted effect size (Field \& Gillett, 2010). Rosenthal's (1979) failsafe $N$ was calculated to be 578. In order for the calculated standardized mean effect size (fixed $=-.37$; random $=-.42$ ) to no longer be significant at $\alpha=.05,578$ studies with an effect of zero would need to be included in the analysis. Orwin's (1983) variation of the failsafe $N$ was calculated to be 37 for a trivial standardized difference in means of -.25 with a mean standardized difference in means of 
-.20 for the missing studies. Orwin's (1983) variation of the failsafe $N$ was calculated to be 67 for a trivial standardized difference in means of -.15 with a mean standardized difference in means of -.10 for the missing studies. Begg and Mazumdar's (1994) rank correlation test indicated that there is no publication bias $(-\mathrm{r}-.35, p \quad .083$, two- tailed). 
Behnken et al. (2009)

Bess (2004)

Christy et al. (2005)

Cosden et al. (2004)

Canales (2011)

Frailing (2010)

Herinckx et al. (2005)

Hiday \& Ray (2010)

Roman (2011)

Steadman et al. (2011c)

Steadman et al. (2011a)

Steadman et al. (2011b)

Steadman et al. (2011d)

Trupin et al. (2003a)

Trupin et al. (2003b)
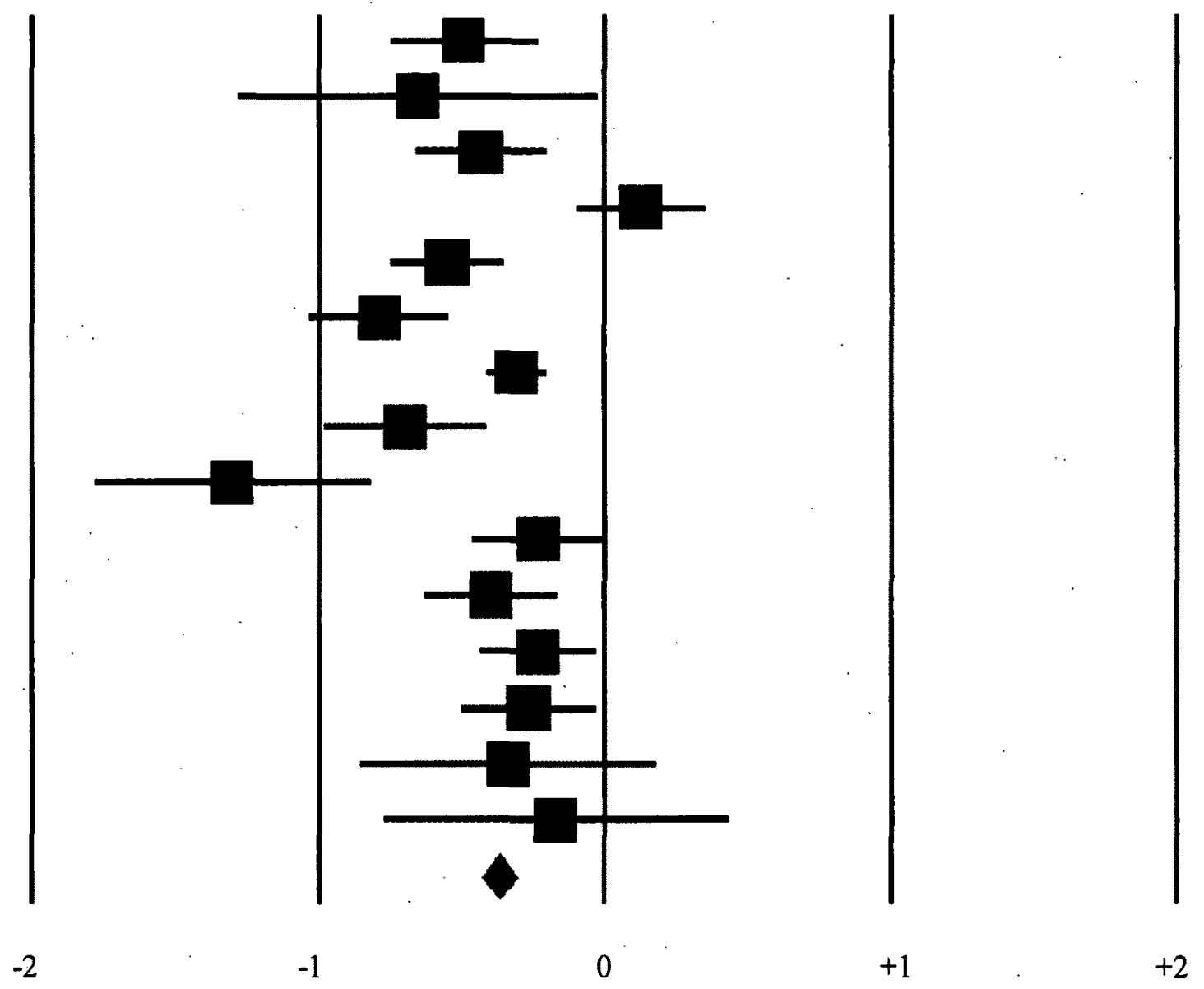

Favours Mental Health Court

Does not Favour Mental Health Court

Figure 1. Meta-analytic results for the single group meta-analysis of criminal offence outcomes. All effect sizes were coded as negative when recidivism was reduced post mental health court involvement. The summary effect is represented by the diamond at the bottom of the figure. 
A $Q$ between-groups moderator analysis was conducted for publication status (published versus unpublished studies). Publication status was not a statistically significant moderator $\left(\chi^{2}(1)=.058, p=.810\right.$; Table 7). A $Q$ between-groups moderator analysis was conducted for the type of index offences the MHC accepts: misdemeanor, felony, or both misdemeanor and felony offences. Type of offences was a statistically significant moderator $\left(\chi^{2} \cdot(1)=4.05, p=.044\right)$, with courts that accepted both misdemeanors and felonies had higher effect sizes $(d=-.48)$ than misdemeanor only MHCs $(d=-.33$; Table 7$)$. Methodological rigor was not assessed in this meta-analysis because the only means of measuring study quality related to the design of comparison groups, and this meta-analytic review did not examine differences between groups. 
Table 7

Moderator Results for Criminal Offences Based on Publication Status of Study, and Mental Health Court Accepted Index Offences

\begin{tabular}{|c|c|c|c|c|c|c|c|}
\hline \multirow[b]{2}{*}{ Moderator } & \multicolumn{2}{|c|}{ Fixed Effects } & \multicolumn{2}{|c|}{ Random Effects } & \multirow[b]{2}{*}{$Q$} & \multirow[b]{2}{*}{$I^{2}$} & \multirow[b]{2}{*}{$k\left(n^{\mathrm{a}}\right)$} \\
\hline & $d$ & $95 \% \mathrm{CI}$ & $d$ & $95 \% \mathrm{CI}$ & & & \\
\hline \multicolumn{8}{|l|}{ Publication Status } \\
\hline All Statuses & -.37 & $-.43,-.31$ & -.42 & $-.56,-.29$ & $60.94 * *$ & 77.03 & $15(1,996)$ \\
\hline Published & -.37 & $-.44,-.31$ & -.40 & $-.51,-.29$ & $23.62^{*}$ & 57.67 & $11(1,398)$ \\
\hline Unpublished & -.36 & $-.49,-.22$ & -.57 & $-1.12,-.01$ & $37.26 * *$ & 91.95 & $4(598)$ \\
\hline \multicolumn{8}{|l|}{ Index Offences } \\
\hline All Offences & -.38 & $-.46,-.31$ & -.49 & $-.70,-.28$ & $53.78 * *$ & 83.27 & $10(1,411)$ \\
\hline Misdemeanors & -.33 & $-.42,-.23$ & -.33 & $-.42,-.23$ & 1.23 & .00 & $4(741)$ \\
\hline \multicolumn{8}{|l|}{ Misdemeanors } \\
\hline \& Felonies & -.48 & $-.60,-.36$ & -.61 & $-1.00,-.22$ & $48.50 * *$ & 89.69 & $6(670)$ \\
\hline
\end{tabular}

Note. $\mathrm{CI}=$ confidence interval. $k=$ number of studies.

$a=$ total number of observations used to calculate the effect, they are not independent.

${ }^{*} \mathrm{p}<.01,{ }^{* *} p<.001$ 


\section{Recidivism Outcomes for Mental Health Court and Comparison Samples}

The second meta-analytic review also examined the efficacy of adult and youth mental health courts in terms of recidivism. The current meta-analysis compared mean recidivism rates for $\mathrm{MHC}$ participants and a comparison sample post-involvement in a $\mathrm{MHC}$, alternative type of treatment, or following processing through the traditional criminal justice system. Depending on the study, recidivism following MHC involvement could have been measured from time of referral, entry into the $\mathrm{MHC}$, or another point of interest. The measure of recidivism used was dependent on the study, with some studies using number or arrests and convictions (Rossman et al., 2012), number of days in detention (Buldum, 2005), and number of charges (Canales, 2011). As for the first meta-analysis, it was often unclear whether the index offence which brought the offender to the MHC was included in each study's analysis. In their evaluation, Hiday and Ray (2010) did indicate that they did not include the key arrest which brought the offender to the MHC, whereas Cosden and colleagues (2004) did not indicate such information. The comparison group varied according to the study and could have been comprised of a traditional court sample (e.g., never referred to the MHC), MHC participants who withdrew from the program, or MHC participants who were expelled from the program, among others (Table 4). Fourteen of the studies had comparison groups who were either never involved with the MHC or were once involved but their participation was terminated. One study (Buldum, 2005) used a comparison sample that had proceeded through the youth MHC but had received a different form of treatment. What was considered the youth MHC sample for the purposes of this study was the group which received Integrated Community Treatment because they received greater mental health care (Buldum, 2005). 
Four studies (Bess, 2004; Cosden et al., 2004; Rossman et al., 2012; Trupin, Richards, Wertheimer, \& Bruschi, 2001) reported data for multiple measures of recidivism, and four studies (Cosden et al., 2005; Canales, 2011; Hiday \& Ray, 2010; Rosșman et al., 2012) included recidivism data for multiple subgroups. Effect sizes were collapsed to create one aggregate mean effect size for the study or for each site if the study was a multisite study. The multisite study of two adult MHCs in New York (Bronx and Brooklyn) by Rossman and colleagues (2012) had to be collapsed into one overall study because the comparison groups included many of the same offenders (Rossman et al., 2012). One of the studies (Buldum, 2005) was of a youth MHC and one study (Canales, 2011) was of an adult MHC in Canada. The remaining thirteen studies were of adult MHCs in the U.S.. Effect sizes were coded so that a negative effect size represented a reduction in recidivism. Twelve studies or $15 \mathrm{MHC}$ sites were included in this meta-analytic review, effect sizes ranged from -.99 to .83 , and the total sample size, including all non-independent observations for each measure of recidivism and subgroup, was large $(N=6,786$; Table 8$)$. 
Table 8

Sample Sizes and Effect Sizes for the Second Meta-Analytic Review by Study $(N=12)$ and Mental Health Court Site $(N=15)$

\begin{tabular}{|c|c|c|c|c|c|}
\hline \multirow[b]{2}{*}{ MHC Study } & \multirow[b]{2}{*}{$\operatorname{MHC} N$} & \multirow[b]{2}{*}{ Comparison $N$} & \multirow[b]{2}{*}{ Cohen's $d$} & \multicolumn{2}{|c|}{$95 \% \mathrm{CI}$} \\
\hline & & & & $L L$ & $U L$ \\
\hline Bess (2004) & 18 & 26 & -.21 & -.81 & .39 \\
\hline Buldum (2005) & 9 & 55 & .83 & .11 & 1.54 \\
\hline Canales (2011) & $90-103 *$ & $35-48 *$ & -.39 & -.65 & -.13 \\
\hline Christy et al. (2005) & 55 & 57 & -.25 & -.63 & .12 \\
\hline Cosden et al. (2004) & $13-108 *$ & $9-79$ & -.16 & -.44 & .12 \\
\hline Frailing (2010) & 86 & 238 & -.99 & -1.25 & -.74 \\
\hline Hiday \& Ray (2010) & 60 & $8-31$ & -.77 & -1.12 & -.39 \\
\hline Neiswender (2005) & 114 & 80 & -.70 & -1.00 & -.41 \\
\hline Roman (2011) & 43 & 46 & -.34 & -.76 & .08 \\
\hline Rossman et al. (2012) & $303-564^{*}$ & $303-564 *$ & -.06 & -.15 & .04 \\
\hline Trupin et al. (2001) & 65 & 82 & .13 & -.20 & .45 \\
\hline Steadman et al. (2011a) & 108 & 146 & -.09 & -.34 & .16 \\
\hline Steadman et al. (2011b) & 136 & 198 & -.13 & -.35 & .09 \\
\hline Steadman et al. (2011c) & 104 & 144 & -.04 & -.30 & .21 \\
\hline
\end{tabular}


Note. $\mathrm{CI}=$ confidence interval; $L L=$ lower limit; $U L=$ upper limit.

$*$ = different measures of one outcome were associated with different sample sizes and so the range of sample sizes are provided. 
Cochran's $Q$ statistic was significant thereby indicating that there is significant heterogeneity across studies and more than would be expected by chance $(Q=83.76, d f=14, p$ $<.001, I^{2}=83.29$; Table 6). Like the $Q$ statistic the $I^{2}$ indicates that there is much variability across studies and most $(83 \%)$ is more than what you would expect by chance (Higgins et al., 2003). With significant variability across studies the meta-analytic results were examined for potential outliers. In this case the most extreme values were not associated with the largest weights therefore there were no outliers. Given that the between study variability was not accounted for by an outlier there is evidence of true variability between the studies (Borenstein et al., 2009).

There were no extreme weights assigned to any one study. The study with the largest assigned weight was the Rossman and colleagues (2012) study. The Rossman and colleagues (2012) study had a weight of 42.17 in the fixed effects analysis and a weight of 8.68 in the random effects analysis. Study weights are partially determined by sample size and in this case, the Rossman and colleagues (2012) study had the largest sample size $(N=867$ including some overlapping sample; Borenstein et al., 2009). An extremely large weight is a more concerning problem for fixed effects analysis because of how the weight is calculated (based only on within- study variance; Borenstein et al., 2009). The Rossman and colleagues (2012) weight is just under $12 \%$ larger than the second largest weight and to the researcher, this was not considered a substantial difference. This finding lends further support to the author's attention being primarily directed to the interpretation of the random effects analysis.

Using the fixed effects method there was a statistically significant reduction in recidivism for MHC participants compared to a comparison sample $(d=-.19,95 \%$ CI [$.25,-.13]$; Table 6). This effect was considered a small effect. Using the random effects 
analysis there was a statistically significant reduction in recidivism for MHC participants compared to a comparison sample $(d=-.25,95 \%$ CI $[-.42,-.08]$; Table 6 ; Figure 2$)$. This effect was considered a small effect. The funnel plot produced by CMA showed no publication bias as there was evidence of symmetry around the mean weighted effect size (Field \& Gillett, 2010). Rosenthal's (1979) failsafe $N$ was calculated to be 150 . In order for the calculated standardized mean effect size (fixed $=-.19$; random $=-.25$ ) to no longer be significant at $\alpha=$ $.05,150$ studies with an effect of zero would need to be included in the analysis. Orwin's (1983) variation of the failsafe $N$ was calculated to be 13 for a trivial standardized difference in means of -.15 with a mean standardized difference in means of -.10 for the missing studies. Begg and Mazumdar's (1994) rank correlation test indicated that there is no publication bias $(\tau=-.14, p=.457$, two-tailed $)$. 
Bess (2004)

Buldum (2005)

Christy et al. (2005)

Cosden et al. (2004)

Canales (2011)

Frailing (2010)

Hiday \& Ray (2010)

Neiswender (2005)

Roman (2011)

Rossman et al. (2012)

Steadman et al. (2011a)

Steadman et al. (2011b)

Steadman et al. (2011c)

Steadman et al. (2011d)

Trupin et al. (2001)

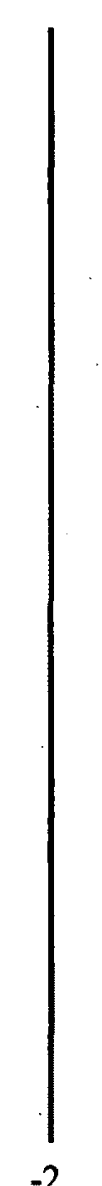

$-2$
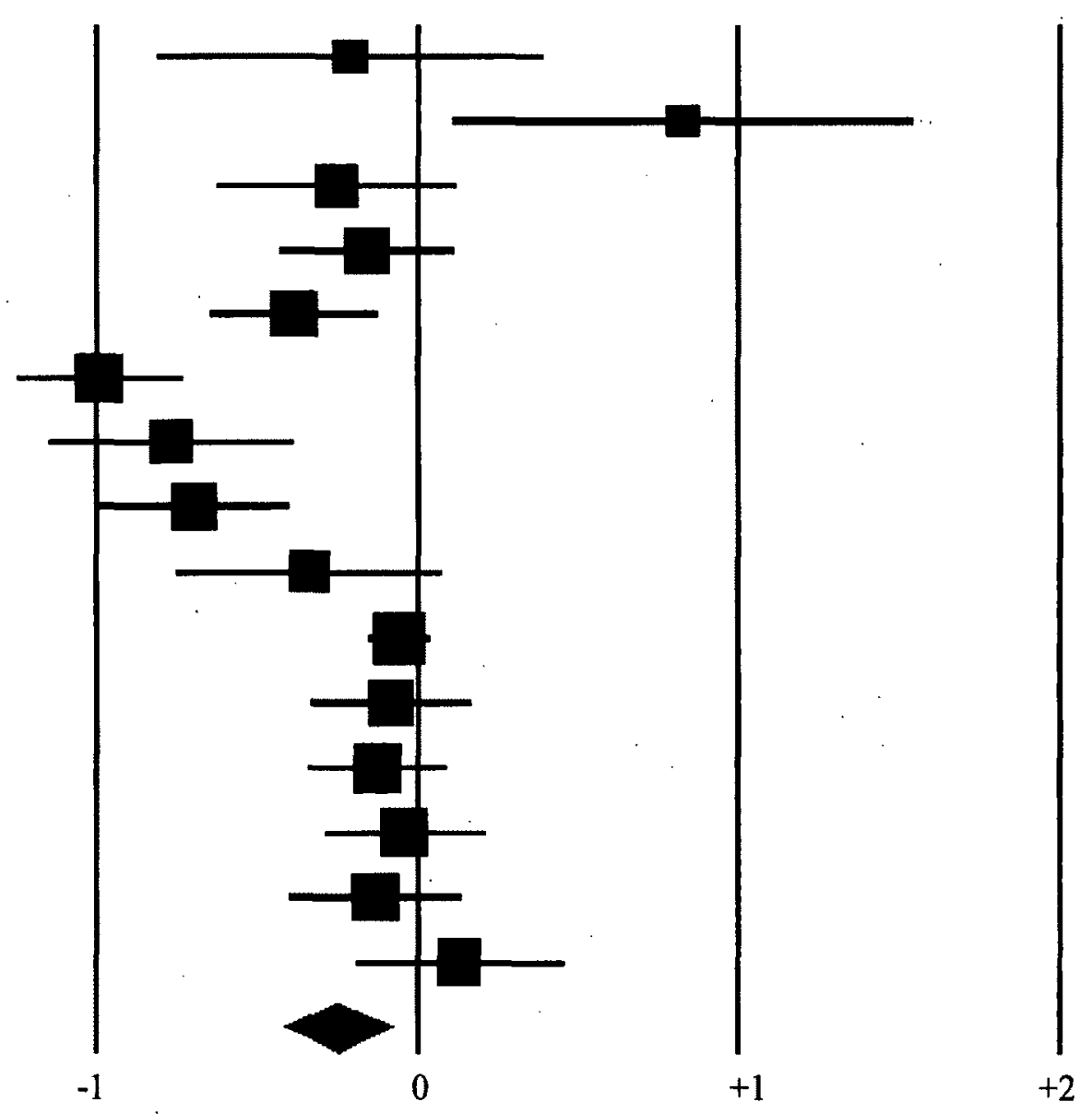

Favours Comparison Group

Favours MHC

Figure 2. Meta-analytic results for the between group meta-analysis of recidivism outcomes. All effect sizes were coded as negative when the mental health court group exhibited less recidivism post mental health court involvement than a comparison sample. Comparison samples may have included mental health court participants who were either expelled or voluntarily withdrew from the program, or a traditional court sample. The summary effect is represented by the diamond at the bottom of the figure. 
A $Q$ between-groups moderator analysis was conducted for publication status (published versus unpublished studies). Publication status was not a statistically significant moderator $\left(\chi^{2}(1)=.03, p=.009\right.$; Table 9). A $Q$ between-groups moderator analysis was conducted for the type of index offences the MHC accepts: misdemeanor, felony, or both misdemeanor and felony offences. Type of index offences was a statistically significant moderator $\left(\chi^{2}(1)=13.94, p<.001\right)$, with MHCs that only accepted misdemeanors having higher effect sizes $(d=-.31)$ than courts that accepted both felonies and misdemeanors $(d=$ -.20; Table 9). As a means to assess the methodological quality of the studies, a $Q$ betweengroups moderator analysis was conducted to compare studies with a true experimental design, against those studies with either a quasi- experimental design with a matched treatment as usual comparison group, with studies where the comparison groups consisted of participants who were expelled, ineligible, or dropped out of the MHC program. Methodological quality was a statistically significant moderator $\left(\chi^{2}(2)=39.87, p<.001\right)$, with studies where the comparison group consisted of offenders who opted out, were expelled, or ineligible for the MHC program having the highest effect sizes $(d=-.55)$, and studies with a matched treatment as usual comparison group having the smallest effect sizes $(d=-.08$; Table 9$)$. Experimental studies had an average mean weighted effect size of $d=-.17$ (Table 9). 
Table 9

Moderator Results for Recidivism Based on Publication Status of Study, and Mental Health Court Accepted Index Offences

\begin{tabular}{|c|c|c|c|c|c|c|c|}
\hline \multirow[b]{2}{*}{ Moderator } & \multicolumn{2}{|c|}{ Fixed Effects } & \multicolumn{2}{|c|}{ Random Effects } & \multirow[b]{2}{*}{$Q$} & \multirow[b]{2}{*}{$I^{2}$} & \multirow[b]{2}{*}{$k\left(n^{\mathrm{a}}\right)$} \\
\hline & $d$ & $95 \% \mathrm{CI}$ & $d$ & $95 \% \mathrm{CI}$ & & & \\
\hline \multicolumn{8}{|l|}{ Publication Status } \\
\hline All Statuses & -.19 & $-.25,-.13$ & -.25 & $-.42,-.08$ & $81.78 * *$ & 82.88 & $15(6,786)$ \\
\hline Published & -.30 & $-.40,-.20$ & -.34 & $-.62,-.05$ & $44.30 * *$ & 86.46 & $7(1,706)$ \\
\hline Unpublished & -.13 & $-.21,-.05$ & -.18 & $-.40, .04$ & $30.70 * *$ & 77.20 & $8(5,080)$ \\
\hline \multicolumn{8}{|l|}{ Index Offences } \\
\hline All Offences & -.22 & $-.29,-.14$ & -.38 & $-.65,-.10$ & $68.92 * *$ & 88.39 & $9(5,469)$ \\
\hline Misdemeanors & -.31 & $-.50,-.12$ & -.28 & $-.78, .22$ & $13.83^{*}$ & 85.54 & $3(600)$ \\
\hline \multicolumn{8}{|l|}{ Misdemeanors } \\
\hline \& Felonies & -.20 & $-.28,-.12$ & -.42 & $-.79,-.06$ & $54.01 * *$ & 90.74 & $6(4,869)$ \\
\hline \multicolumn{8}{|l|}{ Methodological Rigor } \\
\hline All Studies & -.20 & $-.26,-.14$ & -.29 & $-.46,-.12$ & $74.07^{* *}$ & 82.45 & $14(6,722)$ \\
\hline Experimental & -.17 & $-.42, .08$ & -.17 & $-.42, .08$ & .02 & .00 & $2(848)$ \\
\hline TAU and matched & -.08 & $-.15,-.01$ & -.08 & $-.15,-.01$ & 1.45 & .00 & $6(4,538)$ \\
\hline Opt Out/ Expelled/ & & & & & & & \\
\hline Ineligible & -.55 & $-.68,-.42$ & -.52 & $-.84,-.19$ & $32.73 * *$ & 84.72 & $6(1,336)$ \\
\hline
\end{tabular}

Note. $\mathrm{CI}=$ confidence interval. $k=$ number of studies.

${ }^{a}=$ total number of observations used to calculate the effect, they are not independent.

${ }^{*} \mathrm{p}<.01,{ }^{* *} p<.001$ 


\section{Clinical Outcomes for Mental Health Court and Comparison Samples}

The third meta-analytic review examined the efficacy of adult and youth mental health courts in terms of clinical outcomes. Clinical outcomes included measures which directly assessed participants' psychosocial outcomes (e.g., Global Assessment of Functioning (GAF) scores, Brief Psychiatric Rating Scale (BPRS)) and hospitalization outcomes (e.g., number of inpatient or outpatient days, number of emergency room visits). The current metaanalysis compared measures of clinical outcomes for MHC participants and a comparison sample, post mental health court involvement. Depending on the study, clinical outcomes following MHC involvement could have been measured a number of months from time of referral, entry into the MHC, or another point of interest. The comparison group varied according to the study and could have been comprised of a traditional court sample, MHC participants who withdrew from the program or MHC participants who were expelled from the program, among others.

A total of five studies contributed an effect size to this meta-analysis. Four of the five studies (Bess, 2004; Cosden et al., 2004; McNiel, Delucchi, \& Binder, 2011; Wei et al., 2011) had multiple effect sizes that were collapsed to create one aggregate mean effect size for the study. One study (Wei et al., 2011) included post clinical information for multiple group comparisons, and effect sizes were also collapsed across subgroups so the study was used as the unit of analysis. One study (Wei et al., 2011) was of an adult MHC in Canada. The remaining four studies were of adult MHCs in the U.S.. Effect sizes were coded so that a negative effect size represented a reduction in clinical outcomes, and effect sizes ranged from .38 to .43 (Table 10). The total sample size for the present meta-analysis was $N=3,396$, and this includes all non- independent observations for each measure of recidivism and each subgroup. 
Table 10

Study Sample Sizes and Effect Sizes for the Third Meta-Analytic Review $(N=5)$

\begin{tabular}{|c|c|c|c|c|c|}
\hline \multirow[b]{2}{*}{ MHC Study } & \multirow[b]{2}{*}{ MHC N } & \multirow[b]{2}{*}{ Comparison $N$} & \multirow[b]{2}{*}{ Cohen's $d$} & \multicolumn{2}{|c|}{$95 \% \mathrm{CI}$} \\
\hline & & & & $L L$ & $U L$ \\
\hline Bess (2004) & $40-47^{*}$ & $23-3^{*}$ & -.15 & -.64 & .34 \\
\hline Cosden et al. (2004) & $13-108 *$ & $9-79 *$ & -.38 & -.70 & -.05 \\
\hline McNiel et al. (2011) & 96 & 61 & .43 & .05 & .81 \\
\hline Trupin et al. (2000) & 67 & 52 & -.28 & -.64 & .09 \\
\hline Wei et al. (2011) & 93 & $14-26^{*}$ & .32 & -.03 & .66 \\
\hline
\end{tabular}

Note. $\mathrm{CI}=$ confidence interval; $L L=$ lower limit; $U L=$ upper limit.

$*$ = different measures of one outcome were associated with different sample sizes and so the range of sample sizes are provided. 
Cochran's $Q$ statistic was significant thereby indicating that there is significant heterogeneity across studies and more than would be expected by chance $(Q=15.85, d f=4, p$ $<.01, I^{2}=74.76$; Table 6). Like the $Q$ statistic the $I^{2}$ indicates that there is much variability across studies and most (75\%) is more than what you would expect by chance (Higgins et al., 2003). With significant variability across studies the meta-analytic results were examined for potential outliers. There was evidence of an outlier because the Cosden and colleagues (2004) study had the most extreme negative effect size (-.38) and was associated with the largest weight (fixed $=25.91$, random $=21.50$ ). In order to see if the Cosden and colleagues (2004) study was a true outlier, it was excluded from the meta-analysis and the results were re-analyzed. Without the potential outlier the $Q$ statistic was reduced by approximately $40 \%(Q$ statistic $=9.541)$ and as such, the study was not a true outlier (Hanson \& Bussière, 1998). There is support for the existence of true variability between studies, but it should be noted that in small meta-analyses it becomes increasingly difficult to tell which studies are true outliers because the study weights become unstable (Borenstein et al., 2009).

There were no extreme weights assigned to any one study. As mentioned above the study with the largest assigned weight was the Cosden and colleagues (2004) study. The Cosden and colleagues (2004) study had a weight of 25.91 in the fixed effects analysis and a weight of 21.50 in the random effects analysis. The Cosden and colleagues (2004) study had the largest sample size and the assigned study weight was just under $6 \%$ larger than the second largest weight, to the researcher this was not considered a substantial difference. This finding lends further support to the author's attention being primarily directed to the interpretation of the random effects analysis. 
Using the fixed effects method there was not a statistically significant reduction in clinical outcomes for MHC participants compared to a comparison sample $(d=-.02,95 \%$ CI $[-.18, .15]$; Table 6). Using the random effects analysis there was not a statistically significant reduction in clinical outcomes for MHC participants compared to a comparison sample $(d=-.01,95 \%$ CI $[-.34, .32]$; Table 6; Figure 3$)$. The funnel plot produced by CMA showed no publication bias as there was evidence of symmetry around the mean weighted effect size (Field \& Gillett, 2010). Rosenthal's (1979) failsafe $N$ and Orwin's (1983) variation of the failsafe $N$ were not calculated because there was not a statistically significant effect. Begg and Mazumdar's (1994) rank correlation test indicated that there is no publication bias ( $\tau$ $=-.40, p=.327$, two-tailed). 
Bess (2004)

Cosden et al. (2004)

McNiel et al. (2011)

Trupin et al. (2000)

Wei et al. (2011)

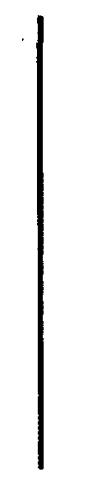

$-2$

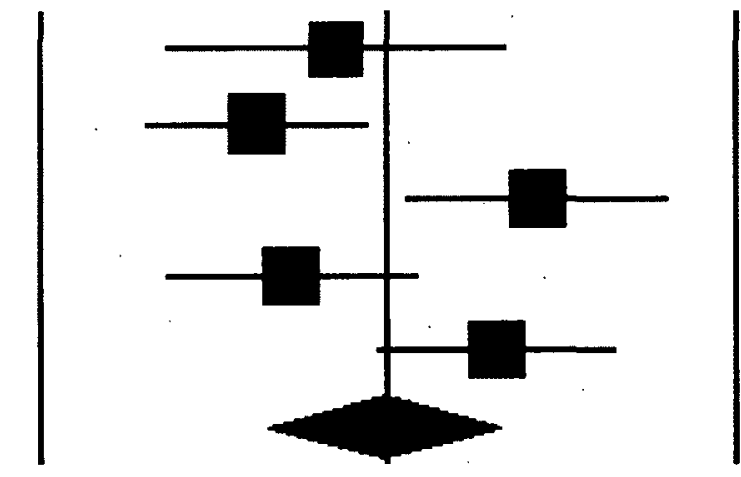

$+1$

Figure 3. Meta-analytic results for the between group meta-analysis of clinical (e.g., psychosocial functioning and hospitalization) outcomes. All effect sizes were coded as negative when the mental health court group exhibited better clinical outcomes post mental health court involvement than a comparison sample. Comparison samples may have included mental health court participants who were either expelled or voluntarily withdrew from the program, or a traditional court sample. The summary effect is represented by the diamond at the bottom of the figure. 


\section{Discussion}

The purpose of this study was to evaluate the efficacy of adult and youth MHCs in

Canada and the U.S. For the present study efficacy was considered to be related to reduced criminal offences, recidivism, and improvements in clinical outcomes (e.g., reduced emergency room visits post MHC involvement). MHCs are a relatively new phenomenon. They were originally constructed in an effort to divert persons with mental illness from the traditional criminal justice system to a type of court (MHC) that is considered to be better equipped to handle their more complex needs. The reason that MHCs are believed to be better equipped to help persons with mental illness is that these courts are comprised of a team with a specialization in mental health and have strong links to community mental health support services. These ties with community health services enable the MHC team is to offer a wide variety of services to the offenders under their jurisdiction. The overall aim of this study was to conduct a critical evaluation of the MHC literature.

This study was the first to include youth MHCs, to include Canadian studies, and to examine criminal offence history outcomes for single group studies in isolation from recidivism outcomes for experimental and quasi- experimental studies. This study had three questions of interest: 1) Do MHC participants experience reduced criminal offences postMHC involvement?; 2) Do MHC participants experience less recidivism post-MHC involvement than a similar comparison group or those who proceed through the traditional criminal justice system?; 3) Do MHC participants experience improvements in clinical outcomes, as measured by psychosocial functioning assessments and reduced hospitalization following MHC participation, than a similar comparison group or those who proceed through the traditional criminal justice system? In order to answer the aforementioned three questions, the author had to conduct three meta-analytic reviews. 
The first meta-analytic review examined mean number of criminal offences prior to $\mathrm{MHC}$ involvement to recidivis̀m post $\mathrm{MHC}$ involvement. Using information aggregated from fifteen MHC sites this review demonstrated that overall there was a small to moderate reduction in criminal offences following involvement in a $\mathrm{MHC}$ (Cohen, 1988; Table 6). The second meta-analytic review examined recidivism post MHC involvement for a $\mathrm{MHC}$ and comparison sample. Using information aggregated from fifteen $\mathrm{MHC}$ sites, the results of this review demonstrated that overall $\mathrm{MHC}$ participants recidivated less than a comparison sample following $\mathrm{MHC}$ involvement (Table 6). There was a small difference in recidivism between the MHC and comparison groups (Cohen, 1988). For comparison purposes this study's summary effect (as measured by Cohen's $d$ ) was transformed into Hedge's $g$, the effect size measure in the Sarteschi and colleagues (2011) meta- analysis. The resultant effect size was the same as the original Cohen's $d$ (Hedge's $g=-.25$ ). The present study's finding is not consistent with the Sarteschi et al. (2011) study where the effect size Hedge's $g=-.54$. The Sarteschi and colleagues (2011) study reported an effect size which was more than twice the current effect size. The result of the current study $(d=-.25)$ did converge with the result of the Cross (2011) meta-analysis where the overall effect size was 0.32 (where a positive effect size represented a reduction in recidivism). The present study's summary effect size was smaller than that reported by Cross (2011), and a smaller effect size in the present study indicated that the current meta-analysis found a smaller reduction in recidivism than the Cross (2011) meta-analysis.

The final meta-analytic review of this study examined the differences in clinical outcomes between MHC participants compared to a similar comparison group or traditional 
court sample post MHC involvement. This study found no effect of MHC involvement on the improvement of clinical outcomes (Table 6). In terms of magnitude, the effect size of this study converged with that of the Cross (2011) meta-analysis $(d=-.09)$. The Cross (2011) meta-analysis used positive effect sizes to represent an improvement in clinical outcomes therefore the author's negative summary effect size indicated that the MHC participants fared worse than the comparison groups. The present study found more favorable results (improvements in clinical outcomes) for the MHC participants.

The differences between the results of the present study and the other meta-analyses may be due to coding procedures and independence of observations. The present study utilized a stringent coding manual in order to more precisely answer the questions at hand. The Cross (2011) and Sarteschi and colleagues (2011) meta-analyses included studies which examined recidivism as a dichotomous outcome and they combined effect sizes calculated from change scores (from pre to post) and means from only one time point (post). The latter method should not have been employed because when using the standardized mean difference (Cohen's $d$ or Hedges's $g$ ) as the effect size, effect sizes calculated on change scores versus at only one time point cannot be combined (Cochrane Collaboration, 2012). Having included studies with dichotomous outcome measures, the previous meta-analyses were including studies which answered fundamentally different research questions (Did they recidivate? Versus How much did they recidivate?; Helmus \& Babchishin, 2012). Combining studies which answer different research questions conjures a common criticism of meta-analyses: that they combine apples and oranges and that the differences will be lost in the creation of a summary effect (Borenstein et al., 2009). The goal of a meta-analysis is to combine inherently different study results while at the same time including studies which are similar enough to 
suitably answer the research question (Borenstein et al., 2009). This author thought that combining studies with recidivism measured as a dichotomous outcome would have been akin to meta-analyzing the proverbial apples and oranges.

In comparison to the two previous meta-analyses the present study was able to offer a more global representation of the efficacy of MHCs. This was achieved by aggregating all relevant criminal history and clinical information from the available studies and utilizing all of this information in the analyses. Any information related to a subgroup within a study or multiple measures of one outcome were included in the creation of the summary effect size for each meta- analysis. Using this coding procedure reduced subjectivity and bias, as the researcher was not able to select the subgroup or measure of an outcome which produced the most favorable result.

The previous meta-analyses violated independence of assumptions whereas this study was conservative in its inclusion of studies, as an attempt to avoid double sampling. Violating independence of observations causes the sample that appears more than once to be assigned more weight while reducing the variability of your analyses, thereby narrowing (underestimating) the confidence interval of the summary effect (Borenstein et al., 2009). Having violated independence of observations may have artificially increased the overall summary effect size (mean weighted effect size) which is why the present study's summary effects for the second and third meta-analyses are smaller than the others.

The two meta-analyses examining criminal offence outcomes included moderator analyses because there was more variability between studies than expected by chance alone. It was expected that the study specific variability (published versus unpublished) and MHC site specific characteristics would explain some of the variability. This was expected because, 
depending on the city in which the MHC was located, treatment resources would vary as would the MHC team overseeing the mental health care of participants. The meta-analyses showed that there was no evidence of publication bias, with unpublished and published studies finding similar effects (Table 7; Table 9). It should be noted, however, that published studies reported higher effect sizes in both of the meta-analytic reviews where moderator analyses were carried out (Table 7; Table 9).

None of the MHCs reported accepting only felony index offences but four ( $27 \%$, reported only accepting misdemeanor offences, six (40\%) reported accepting both misdemeanors and felonies, and five (33\%) did not report this information or it was not able to be reliably coded based on the information supplied (Table 4). For the first meta-analytic review, it was found that the courts which accepted both misdemeanor and felony offences had greater reductions in criminal offences following $\mathrm{MHC}$ involvement than those courts that only accepted misdemeanors (Table 7). Interestingly, the second meta-analytic review demonstrated that when MHCs are compared with comparison groups, those that only accept misdemeanants show greater reductions in recidivism than those that accept both misdemeanants and felons (Table 9). Nevertheless, regardless of type of index offences accepted, MHCs were more efficacious in reducing recidivism than the traditional criminal justice system (Table 7; Table 9).

The rationale behind index offence as a moderator was that courts that accept more serious offences may use jail time as a sanction more often. More serious crimes may require more intensive monitoring (often early on in ones involvement in a $\mathrm{MHC}$ ) or a longer $\mathrm{MHC}$ sentence, more intensive monitoring and a greater amount of time spent in the MHC system may require more scheduled $\mathrm{MHC}$ appearances. Multiple studies cited failure to appear as a 
common reason for re-arrest and, with potentially more scheduled court appearances, there is more opportunity to fail to appear. It is not without possibility that for those participants who may have been monitored more closely, the increased supervision acted as a deterrent. Unfortunately this author cannot confirm that felony offenders received increased court monitoring, as none of the studies touched on this subject; it was expected that more serious crimes warranted greater supervision.

Some studies indicated that persons arrested for a felony offence would be required to spend more time involved in the MHC program than persons arrested for misdemeanor crimes. To reiterate a previous example, Rossman and colleagues (2012) indicated that the Bronx MHC had a mandatory minimum treatment length of 6 months for misdemeanors and 18-24 months for felony offences. Similarly, the Brooklyn MHC has minimum treatment lengths of 12-18 months for misdemeanors and 18-24 months depending on the type of felony offence (Rossman et al., 2012). In this case it is possible that there was greater incentive for felony offenders to cooperate and abide by the terms and conditions of the MHC if it was likely that they would have been found guilty of their crime had they proceeded with regular criminal justice system processing. The motive for participating in the MHC program may be heightened by the fact that offenders may have their charges dismissed. For example, misdemeanants and first-time nonviolent felony offenders who graduate from the Brooklyn MHC have the guilty plea that was entered upon admission into the MHC cleared and all charges dismissed (Rossman et al., 2012).

Finally, the second meta-analytic review also examined a measure of internal validity as a means to examine the extent to which the author was confident in her findings. True 
experimental studies, where participants are randomized to experimental conditions, enable researchers to infer causality between the independent variable and the dependent variable (Taylor \& Asmundson, 2008). When drawing on the conclusions of experimental studies of MHCs, researchers can be more confident that participation in a MHC reduced recidivism whereas in quasi-experimental studies there are more threats to the internal validity of the study and, any differences between groups are observed and not casual differences (Taylor \& Asmundson, 2008). One such threat to the internal validity of quasi-experimental studies relates to selection effects, where differences in groups may be due to other factors not taken into consideration, such as treatment motivation (Taylor \& Asmundson, 2008). The desire to receive mental health care and cooperate with treatment providers may play a pivotal role in the observed differences between quasi-experimental designs. Quasi-experimental evaluations that compare MHC participants to offenders proceeding through the traditional criminal justice system may be less likely to find beneficial effects of the MHC than studies that compare MHC graduates against those that were expelled or dropped out. Further, participants who opt-in and go on to successfully graduate from the MHC may differ on a variety of characteristics from those offenders who were expelled or opted out, such as increased willingness to receive treatment. In describing the samples of the two sites investigated in their multisite study, Trupin and Richards (2003) reported that eligible participants who opted out of the MHC program faced less severe charges than their eligible counterparts who opted into the program, and may face less severe penalties if convicted.

Within the class of quasi-experimental studies there is a continuum of differing levels of quality with MHC studies that strive to match the MHC group and comparison groups on a variety of measures being more internally valid than those evaluations that compare MHC 
graduates with dropouts, and ejected participants. Unfortunately, researchers have noted that it can be challenging to conduct an experimental investigation in a criminal justice setting. In Christy and colleagues (2005) study of the Broward County MHC, the authors noted that the only study design they could employ was a quasi-experimental method because the County's public defender believed that the MHC was, in many regards, a more appropriate option than the traditional court. McNiel and Binder (2007) referred to a similar problem in their research on the efficacy of the San Francisco Behavioral Health Court; in the end they used a quasiexperimental design. This author became acquainted with the Canadian red tape surrounding MHCs when contacting a number of different bodies, and was eventually prevented from conducting a preliminary observational study of the youth MHC in Ottawa, Ontario.

The methodological quality analyses conducted in the second meta-analytic review demonstrated that the quasi-experimental studies which used MHC opt-outs, drop outs, and ineligible participants as the comparison sample had the greatest reductions in recidivism (Table 9). The experimental studies had the second largest reductions in recidivism, followed by quasi- experimental studies, with no difference in recidivism between the MHC samples and the comparison groups (Table 9). Across the three types of quality ranked studies, those with the weakest internal validity found the greatest reductions in recidivism, and consequently demonstrated the greatest support for the efficacy of MHCs.

\section{Implications}

Depending on what is considered the smallest difference of legal importance, the findings of this study may be interpreted as demonstrating that MHCs are an efficacious means to reduce recidivism. Practically speaking this study has demonstrated that involvement in a MHC is linked to a reduction in recidivism, and recidivism for MHC participants appears to be less than that for offenders who received an alternate form of care. If we concentrate on the two 
groups of studies with the higher internal validity, we find either no relationship between MHC participation and reduced recidivism or a small reduction. Independently a number of studies proclaim the clinical benefits of MHCs, but the results of the current meta-analytic review focusing on measures of clinical outcomes runs contrary to the evaluation discourse of MHCs. When considered in isolation of each other, independent studies report improvements in clinical outcomes; when synthesized in one analysis there appear to be no such benefits. It is plausible that, had the number of studies which met the inclusion criteria were greater, there may have been different results.

One of the greatest challenges in conducting meta-analyses on MHCs is handling the variability that exits both between individual MHCs, and the evaluations conducted on them. The courts themselves vary greatly in their legal procedures and the therapeutic services in which they have access to. The MHC judge and specialized treatment team are able to tailor the MHC program to each participant, in part by determining client specific mandatory minimum terms for treatment compliance. The treatment terms include the specific types of interventions the participants will receive while involved in the court. In terms of legal consequences, each court varies in its use of jail time as a sanction for treatment compliance, and the restrictions it imposes on MHC participants. The functioning of each $\mathrm{MHC}$ varies from community to community and is not predictable. As previously noted, a criticism of the existence of MHCs is that they may result in the preferential treatment of offenders by bumping nonoffenders down the wait-list for community health services (Pierce, 2008). Each MHC can only offer services in which it can guarantee to provide to the client, and if offenders cannot be placed on waiting lists then they must be prioritized ahead of persons not receiving court mandated treatment. 
As a whole MHCs may be considered a band aid for a much larger social problem: the inaccessibility and unavailability of health care services across North America in general; there is now some evidence that indeed their existence is beneficial. This study has shown that they are in fact advantageous to the people they serve, but are they a disadvantage to the people they don't serve? MHCs should be questioned for their possible redirection of invaluable and hard to come by health care services from the general public to adult and young offenders. Adequate health care is already at a premium today, there are increasingly greater physician shortages, and are we denying help to those who are already on preexisting community health care wait lists? If so, is it reasonably justifiable? Is there a way in which funding can be directed to existent established institutional mental health care or diversionary practices rather than creating a new, more friendly, treatment-orientated judicial system? This is not to say that treatment and rehabilitation are not our end goal, simply put, an entire body of research has already established that rehabilitation works, but should we be spending our time on enhancing sound practices or creating new ones? (Andrews, Zinger, Hoge, Bonta, Gendreau, \& Cullen, 1990; Illescas, Sánchez-Meca, \& Genovés, 2001).

MHCs offer a conflicting message of the way in which the North American criminal justice systems function. MHCs are a judicially mandated form of treatment that is built upon two sets of competing philosophical values (offender rehabilitation versus crime and punishment). It appears as though these different philosophical values are not only at odds with each other in the MHC arena but within the Canadian legal system. While the Young Offenders Act was less clear about the intentions of the youth justice system, the Youth Criminal Justice Act $(Y C J A)$ clearly indicates that public safety is of utmost importance and can be protected by an emphasis on the rehabilitation of youth offenders (Tustin \& Lutes, 
2008). This emphasis has permitted the development and functioning of youth MHCs across Canada. Yet at the same time the Declaration of Principle of the $Y C J A$ indicates that a young person is to be penalized for his or her offence and not for the possibility of committing future offences (Latimer, 2009; Tustin \& Lutes, 2008).

\section{Limitations and Future Directions}

The present study is lacking a more formal measure of methodological quality of the studies included in the meta-analytic reviews. An appropriate measure the author could have used would have been the Collaborative Outcome Data Committee's scales (CODC). The CODC's scales were originally developed to measure quality of studies for sex offender treatment research, but they have been used in a systematic review of the drug treatment court literature (Collaborative Outcome Data Committee, 2007; Public Safety Canada, 2010).

Instead of using recidivism as a dichotomous outcome this study used recidivism measured on a continuous scale. This was partially determined by the nature of the available studies and the different questions that could be answered based on its measurement properties. Recidivism is a variable that naturally has a fair amount of skew which impacts the appropriateness of certain types of analyses, in particular analyses which use means as the measure of interest. There is a possibility that the MHCs may have shown more positive results because of outliers in the comparison samples. A confound in the second meta-analytic review is the fact that treatment as usual may involve being redirected to a Drug Treatment Court, which would result in a comparison between two problem-solving courts. It was often unclear what types of services, if any, offenders received when proceeding through the traditional justice system. With regards to the studies of single groups of MHC participants, not knowing the exact length of time measured prior to MHC participation and the length of 
follow-up periods makes it challenging to draw sound conclusions when conducting program evaluation. Without having detailed information on the methodology of single group studies, it is challenging to ascertain what, if anything, is working and under what circumstances and for whom. Going forward it is important that in comparison group research, the type of care that each group receives be well documented in order to have a better understanding of the standard of care in the criminal justice system. In addition, it is important that there are more comprehensive accounts of the single group evaluations of MHCs. This information combined with more experimental studies, such as a randomized controlled trial, would ascertain whether MHCs reduce recidivism, and whether they are more capable in producing intended outcomes than other forms of accessible treatment.

The term MHC participants should be used loosely as the MHC sample was often comprised of MHC graduates, drop outs, or those that were expelled from the program. Depending on the study the comparison sample could have included participants who had at least minimal involvement in the MHC. That being said, an interesting direction for future research would be to evaluate the efficacy of MHCs for graduates versus those who have only some involvement. It would be interesting to see if having even partial involvement in a MHC could have a meaningful impact and whether graduates exhibit greater reductions in recidivism than partially involved offenders. What is clear is that the MHC literature is still young and there is a need for more rigorous studies comparing their effectiveness to preexisting established practices. 
References

Aas, I. H. (2011). Guidelines for rating Global Assessment of Functioning (GAF). Annals of General Psychiatry, 10(2), 1-11.

Almquist, L., \& Dodd, E. (2009). Mental health courts: A guide to research-informed policy and practice. Council of State Governments Justice Center, New York: New York.

American Academy of Pediatrics. (2000). Insurance coverage of mental health and substance abuse services for children and adolescents: A consensus statement. Pediatrics, 106(4), 860-862.

Anderson, J. F. (2001). What to do about "much ado" about drug courts?. International Journal of Drug Policy, 12, 469-475.

Andrews, D. A., Zinger, I., Hoge, R. D., Bonta, J., Gendreau, P., \& Cullen, F. T. (1990). Does correctional treatment work?: A clinically relevant and psychologically informed metaanalysis. Criminology, 28(3), 369-404.

Arredondo, D. E., Kumli, K., Soto, L., Colin, E., Ornellas, J., Davilla, R. J., Jr., Edwards, L. P., \& Hyman, E. M. (2001). Juvenile mental health court: Rationale and protocols. Juvenile and Family Court Journal, 52(4), 1-19.

Atkins, D. L., Pumariega, A. J., Rogers, K., Montgomery, L., Nybro, C., Jeffers, G., \& Sease, F. (1999). Mental health and incarcerated youth. I: Prevalence and Nature of Psychopathology. Journal of Child and Family Studies, 8(2), 193-204.

Australian Institute of Criminology. (2009, November 13). Mental health courts [court reviews]. Retrieved from http://www.aic.gov.au/criminal_justice_system/c ourts/specialist/mentalhealth.aspx

Babchishin, K. (2012) Meta-analyses [Personal communication]. Ottawa, Ontario: Canada. 
Begg, C. B., \& Mazumdar, M. (1994). Operating characteristics of a rank correlation test for publication bias. Biometrics, 50(4), 1088-1101.

Behnken, M. P., Arredondo, D. E., \& Packman, W. L. (2009). Reduction in recidivism in a juvenile mental health court: A pre- and post- treatment outcome study. Juvenile and Family Court Journal, 60(3), 23-44.

Belenko, S. (1998). Research on drug courts: A critical review. National Drug Court Institute Review, 1(1), 1-43.

Boothroyd, R. A. Mercado, C. C., Poythress, N. G., Christy, A., \& Petrila, J. (2005). Clinical outcomes of defendants in mental health court. Psychiatric Services, 56, 829-834.

Boothroyd, R. A., Poythree, N. G., McGaha, A., \& Petrila, J. (2003). The Broward mental health court: process, outcomes, and service utilization. International Journal of Law and Psychiatry, 26, 55-71.

Borenstein, M., Hedges, L. V., Higgins, J. P. T., \& Rothstein, H. R. (2009). Introduction to metaanalyis. Wiltshire, England: Wiley.

Borzecki, M., \& Wormith, J. S., (1985). The criminalization of psychiatrically ill people: A review with a Canadian perspective. Psychiatric Journal of the University of Ottawa, 10(4), 241-247.

Butterfield, F. (1998, March 5). Asylums behind bars: A special report.; Prisons replace hospitals for the nation's mentally ill. The New York Times. Retrieved from http://www.nytimes.com

Callahan, L., Cocozza, J., Steadman, H. J., \& Tillman, S. (2012). A national survey of U.S. juvenile mental health courts. Psychiatric Services, 63(2), 130-134. 
Canadian Bar Association. (2011, November 17). 10 reasons to oppose Bill C-10. Ottawa, Ontario. Retrieved from http://www.cba.org

Canales, D. (2011). The utility of the level of service/ risk-need-responsivity (ls/rnr) instrument in predicting recidivism for adult mentally ill offenders involved in a mental health court (Master`s thesis). University of New Brunswick, Canada.

Carmichael, D., \& Marchbanks, M. P. (2010, April). Representing the mentally ill offender: An evaluation of advocacy alternatives. College Station, Texas: Texas Task Force on Indigent Defense, Office of Court Administration.

Christy, A., Poythress, N. G., Boothroyd, R. A., Petrila, J., \& Mehra, S. (2005). Evaluating the efficiency and community safety goals of the Broward County Mental Health Court. Behavioral Sciences and the Law, 23, 227-243.

Cochrane Collaboration. (2012). Diversity and Heterogeneity. Retrieved from http://www.cochrane-net.org/openlearning/html/mod13-4.htm

Cocozza, J. J., \& Shufelt, J. L. (2006, June). Juvenile mental health courts: An emerging strategy (Research and Program Brief). Retrieved from http://www.ncmhjj.com

Collaborative Outcome Data Committee (2007). The collaborative outcome data committee's guidelines for the evaluation of sexual offender treatment outcome research [Part 2: CODC Guidelines]. Retrieved from http://www.publicsafety.gc.ca/res/cor/rep/codceng.aspx

Committee on Government Reform. (2004). Incarceration of youth who are waiting for community mental health services in the United States ii. Washington, DC: Minority Staff Special Investigations Division, United States House of Representatives. 
Cosden, M., Ellens, J., Schnell, J., \& Yamini-Diouf, Y. (2004). Evaluation of the Santa Barbara County Mental Health Treatment Court with Intensive Case Management. Gervitz Graduate School of Education, University of California: Santa Barbara.

Cosden, M., Ellens, J., Schnell, J., \& Yamini-Diouf, Y. (2005). Efficacy of a mental health treatment court with assertive community treatment. Behavioral Sciences and the Law, $23,199-214$.

Costello, E. J. (1989). Developments in child psychiatric epidemiology. Journal of the American Academy of Child and Adolescent Psychiatry, 28, 836-841.

Council of State Governments Justice Center. (2012). Criminal Justice Mental Health: Consensus Project. Retrieved from http://consensusproject.org/issue_areas/mental-healthcourts

Cross, B. (2011). Mental health courts effectiveness in reducing recidivism and improving clinical outcomes: A meta-analysis (Master's thesis). Available from Graduate School Theses and Dissertations (Paper 3052).

Davies, M. (2010). Medical Criminal Law Issues [Course lecture]. Carleton University, Ottawa, Ontario.

Dickersin, K., Min, Y-I., \& Meinert, C. L. (1992) Factors influencing publication of research results: Follow-up of applications submitted to two institutional review boards. Journal of the American Medical Association, 267, 374-378.

Eccles, J. S., Midgley, C., Wigfield, A., Buchanan, C. A., Reuman, D., Flanagan, et al. (1993). Development during adolescence: The impact of stage-environment fit on young adolescents' experiences in schools and families. American Psychologist,48(2), 90-101. 
Edens J. F., \& Otto, R. (1997). Prevalence of mental disorders among youth in the juvenile justice system. Focal Point, 11(1), 1-7.

Fazel, S., \& Danesh, J. (2002). Serious mental disorder in 23000 prisoners: A systematic review of 62 surveys. Lancet, 359, 545-550.

Field, A. P. (2005). Is the meta-analysis of correlation coefficients accurate when population correlations vary?. Psychological Methods, 10(4), 444-467.

Field, A. P., \& Gillett, R. (2010). Expert tutorial: How to do a meta-analysis. British Journal of Mathematical and Statistical Psychology, 63, 665-694.

Fisher, W. H., Silver, E., \& Wolff, N. (2006). Beyond criminalization: Toward a criminologically informed framework for mental health policy and services research. Administration and Policy in Mental Health and Mental Health Services Research, 33(5), 544-557.

Geary, P. (2005). Juvenile mental health courts and therapeutic jurisprudence: Facing the challenges posed by youth with mental disabilities in the juvenile justice system. Yale Journal of Health Policy, Law, and Ethics, 2, 671-710.

Goldamp, J. S., \& Irons-Guynn, C. (2000). Emerging judicial strategies for the mentally ill in the criminal caseload: Mental health courts in For Lauderdale, Seattle, San Bernardino, and Anchorage (NCJ 182504). Washington, DC: US Department of Justice.

Goldstrom, I., Jaiquan, F., Henderson, M., Male, A., \& Manderscheid, R. (2000). The availability of mental health services to young people in juvenile justice facilities: A national survey. Retrieved from http:/www.mentalhealth.org/publications/allpubs/

Goss, S. S. (2008). Mental health court programs in rural and nonaffluent jurisdictions. Criminal Justice Review, 33(3), 405-413. 
Griffin, P. A., Steadman, H. J., \& Petrila, J. (2002). The use of criminal charges and sanctions in mental health courts. Psychiatric Services, 53, 1285-1289.

Grudzinskas, Jr. A. J., Clayfield, J. C., Roy-Bujnowski,.K., Fisher, W. H., \& Richardson, M. H. (2005). Integrating the criminal justice system into mental health service delivery: The Worcester diversion experience. Behavioral Sciences and the Law, 23, 277-293.

Gutman, L. M., \& Eccles, J. S. (2007). Stage-environment fit during adolescence: Trajectories of family relations and adolescent outcomes. Developmental Psychology, 43(2), 522-537.

Hanson R. K., \& Brussière, M. T. (1998). Predicting relapse: A meta-analyses of sexual offender recidivism studies. Journal of Consulting and Clinical Psychology, 66(2), 348-362.

Hartford, K., Davies, S., Dobson, C., Dykeman, C., Furhman, B., Hanbidge, J., Irving, D., McIntosh, E., Mendonca, J., Peer, I., Petrenko, M., Voigt, V., State, S., \& Vandervooren, J. (2004). Evidence-based practices in diversion programs for persons with serious mental illness who are in conflict with the law: Literature review and synthesis. Retrieved from http://www.ontario.cmha.ca/justice.asp?cID=5445

Hedges, L. V. (1992). Meta-analysis. Journal of Education Statistics, 17(4), 279-296.

Helmus, L., \& Babchishin, K. (2012). How to conduct a meta-analysis: A 1-day workshop. Workshop held in, Ottawa, Ontario: Canada.

Helmus, L., Hanson, R. K., Babchishin, K. M., \& Mann, R. E. (2012). Attitudes supportive of sexual offending predict recidivism: A meta-analysis. Manuscript submitted for publication, Department of Psychology, Carleton University, Ontario, Ottawa, Canada.

Herinckx, H. A., Swart, S. C., Ama, S. M., Dolezal, C. D., \& King, S. (2005). Rearrest and linkage to mental health services among clients of the Clark county mental health court program. Psychiatric Services, 56(7), 853-857. 
Hiday, V. A., \& Ray; B. (2010). Arrests two years after existing a well-established mental health court. Psychiatric Services, 61(5), 463-468.

Higgins, J., Thompson, S. G., Deeks, J. J., \& Altman, D. G. (2003). Measuring inconsistency in meta-analyses. British Medical Journal, 327, 557-560.

Hora, P. F., Schema, W. G., Rosenthal, J. T. A. (1999). Therapeutic jurisprudence and the drug treatment court movement: Revolutionizing the criminal justice system's response to drug abuse and crime in America. Notre Dame Law Review, 74(2), 439-537.

Illescas, S. R., Sánchez-Meca, J., \& Genovés, V. G. (2001). Treatment of offenders and recidivism: Assessment of the effectiveness of programmes applied in Europe. Psychology in Spain, 5(1), 47-62.

James, D., \& Sawka, E. (2002). Drug treatment courts: Substance abuse intervention within the justice system. ISUMA: Canadian Journal of Policy Research, 3(1), 127-133.

Jensen, E. L., and Gerber, J. (1993). State efforts to construct a social problem: The 1986 war on drugs in Canada. Canadian Journal of Sociology, 18(4), 453-461. ] $=$

Jensen, E. L., Parsons, N. L., and Mosher, C. J. (2007). Adult drug treatment courts: A review. Sociology Compass, 1(2), 552-571.

Linhorst, D. M., Dirks-Linhorst, P. A., Stiffelman, S., Gianino, J., Bernsen, H. L., \& Kelley, J. (2009). Implementing the essential elements of a mental health court: The experiences of a large multijurisdictional suburban county. Journal of Behavioral Health Services \& Research, 37(4), 427-442.

Kaiser, H. A. (2010). Too good to be true: Second thoughts on proliferation of mental health courts [Commentary]. Canadian Journal of Community Mental Health, 29(2), 19-25. 
Kiesler, C. A. (1982). Public and professional myths about mental hospitalization: An empirical reassessment of policy-related beliefs. American Psychologist, 37, 1323-1339. Koyanagi, C. (2007). Learning from history: Deinstitutionalization of people with mental illness as precursor to long-term care reform. Kaiser commission on Medicaid and the uninsured. Retrieved from http://www.kff.org/medicaid/7684.cfm

Kutcher, S., \& McDougall, A. (2009). Problems with access to adolescent mental health care can lead to dealings with the criminal justice system. Paediatrics and Child Health, $14(1), 15-18$

Lamb, R., \& Weinberger, L. E. (1998). Persons with severe mental illness in jails and prisons: A review. Psychiatric Services, 49(4), 483-492.

La Prairie, C., Gliksman, L., Erickson, P. G., Wall, R., \& Newton-Taylor, B. (2002). DTCs-A viable option for Canada? Sentencing issues and preliminary findings from the Toronto court. Substance Use and Misuse, 37(12-13), 1529-1566.

Latimer, C. (2009, October). Youth criminal justice act and youth mental health. Coalition on Community Safety, Health and Well-being. Presentation conducted at the meeting of the Canadian Association of Chiefs of Police.

Lindberg, A. (2009). Costs and benefits of behavioral health court: findings from "examining program costs and outcomes of San Francisco's behavioral health court". San Francisco Collaborative Courts, San Francisco: California.

Lehman, A. F. (1988). A quality of life interview for the chronically mentally ill. Evaluation and Program Planning, 11, 51-62.

Lurigio, A. J. (2001): Effective services for parolees with mental illnesses. Crime and Delinquency, 47(3), 446-461. 
Makany-Rivera, T. (2010). Texas Juvenile Mental Health Courts: An Evaluation and Blueprint for the Future. Texas: Children at Risk.

Markowitz, F. E. (2006). Psychiatric hospital capacity, homelessness, and crime and arrest rates. Criminology, 44(1), 45-72.

Markowitz, F: E. (2010). Mental illness, crime, and violence: Risk, context, and social control. Aggression and Violent Behavior, 16, 36-44.

Mason, B. G. (2005, October). Mental health courts: The newest development in problemsolving courts and therapeutic jurisprudence. The Nebraska Lawyer, 4-8.

McLean Hospital (2012). Measuring Patient Self-Reported Outcomes [BASIS Survey Website]. Retrieved from: http://www.basissurvey.org/basis32/

McNiel, D. E., \& Binder, R. L. (2007). Effectiveness of a mental health court in reducing criminal recidivism and violence. American Journal of Psychiatry, 164, 1395-1403.

McNiel, D. R., Delucchi, K. L., \& Binder, R. L. (2011). Prospective study of the San Francisco behavioral health court: Criminal justice and clinical outcomes at one year follow-up. Retrieved from http://www.sfcourts.org/Modules/ShowDocument.aspx?documentid= 2800

Medicaid (2012). Medicaid: By population [Medicaid Website]. Retrieved from http://www.medicaid.gov/Medicaid- CHIP-Program-Information/By-Population/ByPopulation.html

Mental Health America. (2012). Position Statement 51: Children With Emotional Disorders In The Juvenile Justice System. Retrieved from http://www.mentalhealthamerica.net/ go/position-statements/51 
Mitchell, P. J. (2008, September-October). Youth, mental health, and the law. Institute of Marriage and Family Canada. Retrieved from http://www.imfcanada.org

Moore, M. E., \& Hiday, V. A. (2006). Mental health court outcomes: A comparison of re-arrest and re-arrest severity between mental health court and traditional court participants. Law and Human Behavior, 30, 659-674.

Morris, S. M., Steadman, H. J., \& Veysey, B. M. (1997). Mental health services in United States jails. Criminal Justice and Behavior, 24(1), 3-19.

Moser, A., Campbell, M. A., Canales, D., \& Wei, R. (2011). The Saint John Mental Health Court: putting the program in context. Presentation at The Second North American Correctional and Criminal Justice Psychology Conference, Toronto: Canada.

National Center for Youth Law. (2011, February). Improving outcomes for youth in the juvenile justice system: A review of Alameda County's collaborative mental health court. Retrieved from www.youthlaw.org

National Mental Health Association. (2000). Prevalence of mental disorders among children in the juvenile justice system. Retrieved from http://www.nmha.org

Nolan Jr., J. L. (2002). Drug treatment courts and the disease paradigm. Substance Use and Misuse, 37(12), 1723-1750.

Odegaard, A. M. (2007). Therapeutic jurisprudence: The impact of mental health courts on the criminal justice system. North Dakota Law Review, 83, 225-260.

Oklahoma Department of Mental Health and Substance Abuse Services. (2012). Mental Health Courts in Oklahoma. Retrieved from http://ok.gov/odmhsas/Substance Abuse/Oklahoma_Drug_and_Mental_Health_Courts/Mental_Health_Court/ 
Ontario Ministry of the Attorney General. (1995). Ontario Crown Policy Manual:

Diversion of mentally disordered accused. Toronto: Ministry of the Attorney

General.

Open Society. (2000). The courage to change: A guide for communities to create integrated s ervices for people with co-occuring disorders in the justice system. Delmar, NY: Open Society Institute's Center for Crime, Communities and Culture and the National GAINS Center for People in Contact with the Justice System (SAMHSA Cooperative Agreement), The GAINS Center.

Ormston, E. F. (2010). Commentary: The criminalization of the mentally ill. Canadian Journal of Community Mental Health, 29(2), 5-10.

Paikoff, R. L., \& Brooks-Gunn, J. (1991). Do parent-child relationships change during puberty?. Psychological Bulletin, 110(1), 47-66.

Palermo, G. B. (2010). The Nevada mental health courts. International Journal of Law and Psychiatry, 33, 214-219.

Paus, T. (2005). Mapping brain maturation and cognitive development during adolescence. TRENDS in Cognitive Science, 9(2), 60-68.

Pertila, J., Poythress, N. G., McGaha, A., \& Boothroyd, R. A. (2001). Preliminary observations from an evaluation of the Broward County mental health court. Court Review, 37, 14-22.

Pierce, R. (2008). Queue-Jumping?: Do Mental Health Courts Privilege Criminal Behavior?. Journal of Ethics in Mental Health, 3(2), 1-5.

Polanin, J. (2012) Meta-analyses [Personal communication]. Campbell Collaboration. 
Public Safety Canada. (2010, March). The effectiveness of drug treatment courts [Research Summary]. Retrieved from http://www.publicsafety.gc.ca/res/cor/sum/_fl/cprs201003eng.pdf

Redlich, A. D., Hoover, S., Summers, A., \& Steadman, H. J. (2010). Enrollment in mental health courts: Voluntariness, knowingness, and adjudicative competence. Law and Human Behavior, 34(2), 91-104.

Redlich, A. D., Liu, S., Steadman, H. J., Callahan, L., \& Robbins, P. C. (2012). Is diversion swift?: Comparing mental health court and traditional criminal justice case processing. Criminal Justice and Behavior, 39(4), 420-433.

Redlich, A. D., Steadman, H. J., Callahan, L., Robbins, P. C., Vesselinov, R., \& Özdogru, A. A. (2010). The use of mental health court appearances in supervision. International Journal of Law and Psychiatry, 33, 272-277.

Redlich, A. D., Steadman, H. J., Monahan, J., Petrila, J., \& Griffin, P. A. (2005). The second generation of mental health courts. Psychology, Public Policy, and Law, 11(4), 527-538.

Redlich, A. D., Steadman, H. J., Monahan, J., Robbins, P. C., \& Petrila, J. (2006). Patterns of practice in mental health courts: A national survey. Law and Human Behavior, 30, 347-362.

Rosenbloom, M. (2012). Chlorpromazine and the psychopharmacologic revolution. Journal of the American Medical Association, 287(14), 1860-1861.

Rosenthal, R. (1979). The file drawer problem and tolerance for null results. Psychological Bulletin, 86(3), 638-641.

Rossman, S. B., Willison, J. B., Mallik-Kane, K., Kim, K., Debus-Sherrill, S., \& Downey, P. M. (2012). Criminal justice interventions for offenders with mental illness: Evaluation of 
mental health courts in Bronx and Brooklyn, New York (UI Project No. 07745-007-00). National Institute of Justice: United States.

Rutherford, M. (2010). Blurring the boundaries: The convergence of mental health and criminal justice policy, legislation, systems and practice. London: Sainsbury Centre for Mental Health.

Saint John Mental Health Court. (2009). On the edge [Annual Report]. Retrieved from http://www.mentalhealthcourt-sj.com/summary.html

Sarteschi, C. A. (2009). Assessing the effectiveness of mental health courts: A meta-analysis of clinical and recidivism outcomes (Doctoral dissertation). University of Pittsburgh, Pittsburgh.

Sarteschi, C. M., Vaughn, M. G., \& Kim, K. (2011). Assessing the effectiveness of mental health courts: A quantitative review. Journal of Criminal Justice, 39, 12- 20.

Schneider, R. D. (2008). Mental health courts. Current Opinion in Psychiatry, 21, 1-4.

Schneider, R. D. (2010). Mental health courts and diversion programs: A global survey. International Journal of Law and Psychiatry, 33, 201-206.

Schneider, R. D. (2011). Adult mental health courts [Personal communication]. Old City Hall, Toronto, Ontario.

Schneider, R. D., Bloom, H., Heerema, M. (2007). Mental health courts: Decriminalizing the mentally ill. Toronto, Ontario: Irwin Law.

Schwartz, E. (2008, February 7). Mental Health Courts: How special courts can serve justice and help mentally ill offenders. Retrieved from http://consensusproject.

org/media/mental_health_courts_how_special_courts_can_serve_justice_and_hel p_mentally_ill_offenders 
Scott, E. (2008). Canada's first youth mental health court launches. Cross Currents: The Journal of Addiction and Mental Health, 12(1). Retrieved from http://www.camh crosscurrents.net

Sealy, P., \& Whitehead, P. (2004). Forty years of deinstitutionalization of psychiatric services in Canada: An empirical assessment. Canadian Journal of Psychiatry, 49, 249257.

Shadish, W. R., Jr. (1989). Private-sector care for chronically mentally ill individuals: The more things change, the more they stay the same. American Psychologist, 44(8), 1142-1147.

Sibbald, B., \& Roland, M. (1998). Understanding controlled trials: Why are randomised controlled trials important?. British Medical Journal, 316, 201.

Skeem, J., Manchak, S., \& Peterson, J. (2011). Correctional policy for offenders with mental disorder: Creating a new paradigm for recidivism reduction. Law and Human Behavior, $35,110-126$.

Slate, R. N. (2003). From the jailhouse to capitol hill: Impacting mental health court legislation and defining what constitutes a mental health court. Crime and Delinquency, $49(1), 6-29$.

Slinger, E., \& Roesch, R. (2010). Problem-solving courts in Canada: A review and a call for empirically-based evaluation methods. International Journal of Law and Psychiatry, 33, 258-264.

Soper, D. (2012). Statistics calculators: $P$-value calculator for a chi-square test [Online Statistics Calculator]. Retrieved from http://www.danielsoper.com/statcalc3/calc.aspx?id=11

Standing Senate Committee on Social Affairs, Science and Technology. 2006. Out of the Shadows At Last: Transforming Mental Health, Mental Illness and Addiction 
Services in Canada. Final Report of The Standing Senate Committee on Social Affairs, Science and Technology. Retrieved from http://www.parl.gc.ca/39/1/ parlbus/commbus/senate/com-e/soci-e/rep-e/pdf/rep02may06part1-e.pdf

Steadman, H. J., Davidson, S., Brown, C. (2001). Mental health courts: Their promise and unanswered questions. Psychiatric Services, 52(4), 457-458.

Steadman, H. J., Redlich, A., Callahan, L., Robbins, P. C., \& Vesselinov, R. (2011). Effect of mental health courts on arrests and jail days: A multisite study. Archives of General Psychiatry, 68(2), 167-172.

Steinberg, L., \& Silverberg, S. B. (1986). The vicissitudes of autonomy in early adolescence. Child Development, 57(4), 841-851.

Stone, T. H. (1997). Therapeutic implications of incarceration for persons with severe mental disorders: Searching for rational health policy. American Journal of Criminal Law, 24, 283-358.

Sunshine, J., \& Tyler, T. R. (2003). The role of procedural justice and legitimacy in shaping public support for policing. Law and Society Review, 513, 519-521.

Tarter, R. E. (2002). Etiology of adolescent substance abuse: A developmental perspective. The American Journal of Addictions, 11, 171-191.

Taylor, S., \& Asmundson, G. J. G. (2008). Internal and external validity in clinical research. In D. McKay (Ed.), Handbook of Research Methods in Abnormal and Clinical Psychology (pp. 23-34).Thousand Oaks, CA: Sage.

Teplin, L. A. (1990). The prevalence of severe mental disorder among male urban jail detainees: Comparison with the epidemiologic catchment area program. American Journal of Public Health, 80(6), 663-669. 
Teplin, L. A., \& Pruett, N. S. (1992). Police as streetcorner psychiatrist: Managing the mentally ill. International Journal of Law and Psychiatry, 15; 139-16.

Timmons-Mitchell, J., Brown, C., Schulz, S. C., Webster, S. E., Underwood, L. A., \& Semple, W. E. (1997). Comparing the mental health needs of female and male incarcerated juvenile delinquents. Behavioral Sciences and the Law, 15, 195-202.

Toki, V. (2010). Therapeutic jurisprudence and mental health courts for Maori. International Journal of Law and Psychiatry, 33, 440-447.

Torrey, E. F. (1995). Editorial: Jails and prisons-America's new mental hospitals. American Journal of Public Health, 85(12), 1611-1613.

Torrey, E. F., Entsminger, K., Geller, J., Stanley, J., \& Jaffe, J. (2008). The shortage of public hospital beds for mentally ill persons. Arlington, Virginia: Treatment Advocacy Center.

Trupin, E., \& Richards, H. (2003). Seattle's mental health courts: Early indicators of effectiveness. International Journal of Law and Psychiatry, 26, 33-53.

Trupin, E., Richards, H., Wertheimer, D. M., \& Bruschi, C. (2001). City of Seattle, Seattle Municipal Court Mental Health Court, Evaluation Report. Seattle, Washington: United States.

Tustin, L., \& Lutes, R. E. (2008). A guide to the youth criminal justice act. Canada: LexisNexis.

Tyler, T. R., \& Fagan, J. (2008). Legitimacy and cooperation: Why do people help the police fight in their communities?. Ohio State Journal of Criminal Law, 6, 231-275.

Tyuse, S. W., \& Linhorst, D. M. (2005). Drug courts and mental health courts: Implications for social work. Health and Social Work, 30(3), 233-240.

University of Laurier Library. (2012, January 26). Scholars Portal. Retrived from: http://library.wlu.ca/scholarsportal 
Vevea, J. L., \& Woods, C. M. (2005). Publication bias in research synthesis: Sensitivity analysis using a priori weight functions. Psychological Methods, 10(4), 428-443.

Wales, H. W., Hiday, V. A., Ray, B. (2010). Procedural justice and the mental health court judge's role in reducing recidvism. International Journal of Law and Psychiatry, 33, $265-$ 271.

Watson, A., Hanrahan, P., Luchins, D., \& Lurigio, A. (2001). Mental health courts and the complex issues of mentally ill offenders. Psychiatric Services, 52(4), 477-481.

Watson, A., Luchins, D., Hanrahan, P., Heyrman, M. J., \& Lurigio, A. (2000). Mental health courts: Promises and limitations. Journal of the American Academy of Psychiatry and the Law, 28, 476-482.

Weekes, J., Mugford, R., Bourgon, G., Price, S., (2009). Drug Treatment court FAQ's. Ottawa, Ontario: Canadian Centre on Substance Abuse.

Wei, R., Campbell, M. A., \& Canales, D. (2011). Reduction in criminogenic needs risk as a function of mental health court involvement. Presentation at The Second North American Correctional and Criminal Justice Psychology Conference, Toronto: Canada.

Werb, D., Elliot, R., Fischer, B., Wood, E., Montaner, J, and Kerr, T. (2007). Drug treatment courts in Canada: An evidence-based review. HIV/AIDS Policy and Law Review, 12(2/3), 12-17.

Wilson, H., \& Hoge, R. (in press). The effect of youth diversion programs on recidivism: A meta-analytic review. Criminal Justice and Behavior.

Winick, B. J. (1997). The jurisprudence of therapeutic jurisprudence. Psychology, Public Policy and Law, 3(1), 184-206. 
Wolff, N., \& Pogorzelski, W. (2005). Measuring the effectiveness of mental health courts: Challenges and recommendations. Psychology, Public Policy, and Law, 11(4), 539-569.

World Health Organization. (2003). Investing in mental health. Retrieved from

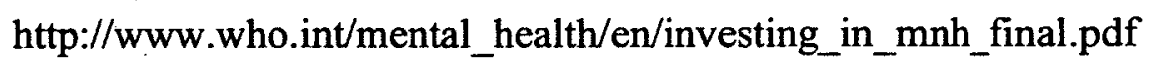

Yurgelun-Todd, D. (2007). Emotional and cognitive changes during adolescence. Current Opinion in Neurobiology, 17, 251-257. 


\section{Appendix}

\section{CODING MANUAL}

The inclusion criteria is as follows:

(1) Available in English; (2) Completed (not in progress); (3) Studies conducted in Canada or the United States; (4) Youth or Adult Mental Health Court; (5) MHC studies of youth and adults of all ages were included so long as mental health was a primary focus of the court; (6) Sufficient statistical results to permit calculation of at least one effect size; (7) Single group (pre-post), experimental or quasiexperimental study design; (8) At least one quantifiable clinical (e.g., measures of psychosocial functioning or hospitalization), criminal offence, or recidivism outcome. Quasi-experimental studies are those with comparison groups but lack random assignment of participants to the intervention.

Studies that met the above aforementioned criteria were assigned a study identification number and subsequently coded. When two or more studies used the same sample, the two studies shared the same primary identification number (e.g., 1) and the earliest study was given the sub-study identifier.I with all other studies assigned subsequently higher sub-study identifiers. When there was a multisite study the first sample was given a sub-identifier of .01 with all other samples having subsequently higher sub-identifiers.

MHCs:

- Calculating the standardized mean difference between two independent groups for recidivism and clinical outcomes

- Calculating the standardized mean difference for single groups (pre-post design) for recidivism

If a study includes separate information for top stanine include top stanine results and create a composite score for all results per study.

If a study does not have a true comparison group but results are reported for graduates, those who voluntarily withdrew from the program, and those ejected from the program include information for all three groups and create a composite score for the study collapsed across all results.

If races/ ethnicities are listed and there is an other category, for any race/ ethnicity not listed put N.A. However if no other category and a racel ethnicity is missing, please put 0 for number of participants and 0 for percentage.

If the same outcome of interest is presented twice in an article, the one with the longest follow-up period is to be used. If however it is unclear which version of the outcome had the longest follow-up period, the version that is the better measure or has the largest sample size is to be 
used. For example, if follow-up data is available for a different length of time between comparison groups but for both groups the longest follow-up period is less than a year, average results rather than annualized data is the better measure because the annualized rates have to be inferred. 


\section{COVER SHEET}

Study Number:

Study Title:

Study Author(s):

Source of Study (including journal name, volume, issue number, year):

Study Notes:

Variables Included (Please circle):

1. Clinical (e.g., psychosocial outcomes and hospitalization outcomes)

2. Recidivism 


\section{Overall Study Coding:}

1) Study Number:

2) Year of Publication:

3) Is this a single or multisite study?:

$0=$ Single

$1=$ Multisite

4) Study Type (Please circle all that apply):

0 . Published

i. If published, peer reviewed or not:

$$
\begin{aligned}
& 0=\text { not peer reviewed } \\
& 1=\text { peer reviewed }
\end{aligned}
$$

1. Ph.D. Dissertation

2. M.A. Thesis

3. Technical Report (Governmental Report)

4. Paper Presented at a Conference

5. Poster Presented at a Conference

6. Unpublished Manuscript

7. Book (Includes Chapter of a Book)

9. Other

5) Study Design:

$0=$ Single Group (e.g. pre-post)

$1=$ Experimental (e.g., randomization)

$2=$ Quasi-Experimental (e.g., comparison group)

The following questions are for each MHC included in the study.

6) Country of MHC:

$$
0=\text { Canada }
$$




$$
1=\mathrm{US}
$$

7) Abbreviation of State/ Province of MHC (if not indicated please put N.A.):

8) County or City MHC located in (if not indicated please put N.A.):

9) Name of MHC Court (If not listed please write N.A.):

10) Adult or Youth MHC?:

$1=$ adult

$2=$ youth

11) Dual Diagnosis Exclusive Court?

$$
\begin{aligned}
& 0=\text { no } \\
& 1=\text { yes } \\
& 9=\text { do not know }
\end{aligned}
$$

12) What type of offenses does the MHC accept?:

$$
\begin{aligned}
& 0=\text { Misdemeanour } \\
& 1=\text { Felony } \\
& 2=\text { Both Felony \& Misdemeanour } \\
& 9=\text { do not know }
\end{aligned}
$$

13) Is the MHC pre-plea or post-plea?:

$$
\begin{aligned}
& 0=\text { pre-plea } \\
& 1=\text { post-plea } \\
& 2=\text { both pre-plea and post-plea } \\
& 9=\text { Don't know }
\end{aligned}
$$

14) Was there a comparison sample? (Please circle all that apply):

$0=$ no

$1=$ yes

If yes, was the comparison sample:

1. Traditional Court Sample (e.g., any sample that did not go through a MHC)

2. Community Treatment

3. Offenders who were expelled or withdrew from the MHC.

4. Other:

If Other Please specify: 
15) Number \& Percentage of Graduates (If not available please put N.A.):

$\mathrm{N}=$

$\%=$

16) Number \& Percentage of MHC noncompleters (Noncompleters = those who were expelled or withdrew from the program. If not available please put N.A.):

$\mathrm{N}=$

$\%=$

17) Number \& Percentage of MHC noncompleters due to expulsion (If not available please put N.A.):

$\mathrm{N}=$

$\%=$

18) Number \& Percentage of MHC noncompleters who withdrew from the program after having been enrolled (If not available please put N.A.):

$\mathrm{N}=$

19) Average length of time (and SD) and median length of time in MHC. If not available please put N.A.:

Mean $=$ $\mathrm{SD}$ of Mean $=$

Median $=$

20) Was there a minimum amount of time one was required to stay in the MHC for?:

$$
\begin{aligned}
& 0=\text { No } \\
& 1=\text { Yes } \\
& 9=\text { Not Indicated }
\end{aligned}
$$

If yes, please specify? If not indicated please write N.A.

21) If there is a comparison group, what was the average length of time (and SD) and median length of time in that group (e.g., traditional court)? If not available please put N.A. or if no comparison group, please skip (do not write anything):

Mean $=$ $\mathrm{SD}$ of Mean $=$

Median $=$ 
The following questions ONLY pertain to the ENTIRE sample for YOUTH studies:

22) Mean age (and SD) of sample (If not available please put N.A.):

Mean $=$ $\mathrm{SD}$ of Mean $=$

23) Age range of participants (If not available please put N.A.):

24) Number \& Percentage of males (If not available please put N.A.):

$\mathrm{N}=$

$\%=$

25) Number \& Percentage of females (If not available please put N.A.):

$\mathrm{N}=$

$\%=$

26) Number \& Percentage of White Participants (If not available write N.A.):

$\mathrm{N}=$

$\%=$

27) Number \& Percentage of African American Participants (If not available write N.A:): $\mathrm{N}=$ $\%=$

28) Number \& Percentage of Hispanic Participants (If not available write N.A.): $\mathrm{N}=$ $\%=$

29) Common Diagnoses (If not available please write N.A.):

a. $\mathbf{n}$ and percentage of participants diagnosed With Schizophrenia:

$\mathrm{N}=$ $\%=$

b. $\mathrm{n}$ and percentage of participants diagnosed with Bipolar Disorders:

$\mathrm{N}=$ $\%=$

c. $\mathrm{n}$ and percentage of participants diagnosed with Depressive Disorders:

$\mathrm{N}=$ $\%=$ 


\section{The following questions ONLY pertain to the MHC sample:}

30) Mean age (and SD) of sample (If not available please put N.A.):

Mean $=$ $\mathrm{SD}$ of Mean=

31) Age range of participants (If not available please put N.A.):

32) Number \& Percentage of males (If not available please put N.A.):

$\mathrm{N}=$

$\%=$

33) Number \& Percentage of females (If not available please put N.A.):

$\mathrm{N}=$

$\%=$

34) Number \& Percentage of White Participants (If not available write N.A.):

$\mathrm{N}=$ $\%=$

35) Number \& Percentage of African American Participants (If not available write N.A.): $\mathrm{N}=$ $\%=$

36) Number \& Percentage of Hispanic Participants (If not available write N.A.): $\mathrm{N}=$ $\%=$

37) Common Diagnoses (If not available please write N.A.):

d. $\mathrm{n}$ and percentage of participants diagnosed With Schizophrenia: $\mathrm{N}=$ $\%=$

e. $\mathrm{n}$ and percentage of participants diagnosed with Bipolar Disorders: $\mathrm{N}=$ $\%=$

f. $\mathrm{n}$ and percentage of participants diagnosed with Depressive Disorders: $\mathrm{N}=$ $\%=$ 
The following questions ONLY pertain to the Comparison sample (if there is one). If there is no comparison sample please skip these questions.:

38.).Mean age of sample (If not available please put N.A.):

Mean $=$

$\mathrm{SD}$ of Mean $=$

39) Age range of participants (If not available please put N.A.):

40) Number \& Percentage of males (If not available please put N.A.):

$\mathrm{N}=$ $\%=$

41) Number \& Percentage of females (If not available please put N.A.):

$\mathrm{N}=$ $\%=$

42) Number \& Percentage of White Participants (If not available write N.A.):

$\mathrm{N}=$ $\%=$

43) Number \& Percentage of African American Participants (If not available write N.A.): $\mathrm{N}=$ $\%=$

44) Number \& Percentage of Hispanic Participants (If not available write N.A.): $\mathrm{N}=$ $\%=$

45) Common Diagnoses (If not available please write N.A.):

g. $\mathrm{n}$ and percentage of participants diagnosed With Schizophrenia:

$\mathrm{N}=$ $\%=$

h. $\mathrm{n}$ and percentage of participants diagnosed with Bipolar Disorders:

$\mathrm{N}=$ $\%=$

i. $\mathrm{n}$ and percentage of participants diagnosed with Depressive Disorders: $\mathrm{N}=$ $\%=$ 
VARIABLE CODING

Study Number:

Variable of Interest:

Measure Name:

Description of Measure:

Page \#(s)

Table \#(s)

Statistic:

Means \& Standard Deviations:

\begin{tabular}{|l|l|l|l|}
\hline & Sample Size $(n)$ & Mean $(M)$ & $\begin{array}{l}\text { Standard Deviation } \\
(S D)\end{array}$ \\
\hline MHC Group & & & \\
\hline Comparison Group & & & \\
& & & \\
\hline
\end{tabular}

1. $t / F$

2. $d$

3. $r$

4. Means and standard deviations 
5. $p$ value

6. $p$ value with effect direction 


\section{Clinical Outcome Information:}

Only answer the following based on what will be analyzed in one of the meta-analyses

1) Name of scale or measure:

2) When was the scale measured? Please circle all that apply:

$$
\begin{aligned}
& 0=\text { Pre } \\
& 1=\text { During } \\
& 2=\text { Post }
\end{aligned}
$$

3) If applicable, please specify:

i) Number of months pre:

ii) Number of months during:

iii) Number of months post: 


\section{Hospitalization Outcome:}

Only answer the following based on what will be analyzed in one of the meta-analyses

1) At which time points was hospitalization measured? Please circle all that apply:

$$
\begin{aligned}
& 0=\text { Pre } \\
& 1=\text { During } \\
& 2=\text { Post }
\end{aligned}
$$

2) If applicable, please specify:

i) Number of months pre:

ii). Number of months during:

iii) Number of months post:

3) Which sources were used to determine whether a participant was hospitalized (e.g., hospital records)?

$0=$ Country specific (National) hospital records

$1=$ Local (e.g., state, provincial, city) hospital records

$2=$ Self-report

$3=$ Institution specific records

$4=$ Unknown (e.g., not mentioned)

$5=$ Not classifiable 


\section{Recidivism Outcome:}

Only answer the following based on what will be analyzed in one of the meta-analyses

1) At which time points was recidivism measured? Please circle all that apply.

$$
\begin{aligned}
& 0=\text { Pre } \\
& 1=\text { During } \\
& 2=\text { Post }
\end{aligned}
$$

2) If applicable, please specify:

i) Number of months pre:

ii) Number of months during:

iii) Number of months post:

3) Which sources were used in order to determine whether a participant recidivated (e.g., criminal records database)? Please circle all that apply.

$0=$ Country specific (National) criminal records

$1=$ Local (e.g., state, provincial, city) criminal records (e.g., state departments of correction)

$2=$ Self-report

3 = Institution specific records (e.g., local jail records or $\mathrm{MHC}$ administrative records)

$4=$ Unknown (e.g., not mentioned)

$5=$ Not classifiable 